\title{
Melitid amphipods of Barrow Island, Western Australia Part II - recent discoveries
}

\author{
J. H. Bradbury \\ Department of Environmental Biology, University of Adelaide, Adelaide, South Australia 5005, Australia \\ email: john.bradbury@adelaide.edu.au
}

\begin{abstract}
Investigation of new sites of underground waters on Barrow Island, Western Australia, yielded amphipods of the families Melitidae and Bogidiellidae at seven locations not previously sampled. Described species of the genus Nedsia, family Melitidae, were found at several of these locations; three new species of the genus are described from two sites. Keys to the known species of Nedsia are extended to include the three new ones.
\end{abstract}

\section{INTRODUCTION}

Barrow Island, Western Australia, $20^{\circ} 46^{\prime} \mathrm{S}$, $115^{\circ} 24^{\prime} \mathrm{E}$, is an isolated extension of the Cape Range, situated approximately $55 \mathrm{~km}$ west of the mainland coast. Little, or no surface water is to be found across the greater area of the island, and permanent surface waters are absent. Aquatic invertebrates nevertheless abound, but are restricted to cave systems and ground water, which are widespread. As reported previously (Bradbury and Williams 1996a, b, 1997; Humphreys 1993a,b, 1999, 2000), extensive sampling, commonly associated with oil exploration and exploitation, has revealed the frequent presence of amphipod species. In all, seven species of the genus Nedsia (Barnard and Williams 1995) attributed to the family Melitidae, one species of the genus Bogidomma (Bradbury and Williams 1996a), family Bogidiellidae, and one species of the genus Liagoceradocus, family Hadziidae, have been described from Barrow Island (Bradbury and Williams 1996b).

Amphipod species of the melitoid (hadzioid) complex are distributed widely over the continent (Bradbury and Williams, 1999). The melitoid (hadzioid) complex is not, however, clearly demarcated and has been the subject of review for some time, as yet without resolution. For the time being, therefore, and following Barnard and Williams (1995), taxa described here are attributed to the family Melitidae. Melitids of Barrow Island, the Nullarbor Plain and the Flinders Ranges all appear to be marine strandings and/or invaders from periods of inundation during the Cretaceous, between 120 and 100 million years ago (Bradbury and Williams, 1997; Paine, 1990). These once marine regimens encompass much of inland Australia, as well as many coastal regions, and considerable numbers of new species might reasonably be expected among collections yet to be analysed; eleven species have been described to date (Barnard and Williams, 1995; Bradbury and Williams, 1996a; Bradbury and Eberhard, 2000). All such melitids are hypogean and have well developed stygobiont characteristics, including blindness, lack of pigmentation, fragility and attenuation of the appendages (Holsinger, 1994), and in some regions display considerable endemism (Bradbury, 2000).

This paper reports on the analysis of a further twenty samples, taken between October 1998 and April 1999, from seven sites on Barrow Island. Three new species of the genus Nedsia, family Melitidae are described. All are small, ranging in size between 2 and $4 \mathrm{~mm}$. Species of the family Bogidiellidae were also present in small numbers; these shall be described at a later date.

\section{METHODS OF DISSECTION AND DESCRIPTION}

The notation $\mathbf{M}$, with an appended number, indicates the position of an object as a fraction of the distance from the base to the apex of an appendage; $\mathbf{S}$ large spine; $\mathbf{s}$, small spine. Abbreviations used in the figures are as follows: $\mathbf{A}$, antenna; Abd, abdomen; acc, accessory; C, coxa; $\mathbf{d}$, dorsal; dact, dactylus; E, epimeron; fl, flake; flag, flagellum; $\mathbf{g}$, gill; $\mathbf{G}$, gnathopod; Hd, head; $\mathbf{i}$, inner; juv, juvenile; L, left; lac, lacinia mobilis; LL, lower lip; MD, mandible; med, medial; mol, molar; MP, maxilliped; $\mathbf{M X}$, maxilla; $\mathbf{o}$, outer; $\mathbf{O}$, oostegite; opp, opposite; p, palp; $\mathbf{P}$, pereopod; $P C$, prebuccal complex; pl, plate; $\mathbf{P p}$, pleopod; $\mathbf{R}$, right; sp, spine; sq, square view; sr, setae removed (sometimes marked by sockets); st, sternal gill; $T$, telson; $U$, uropod; UL, upper lip; UR, urosome; 1, 2, 3..7, first, second, third ..seventh article, segment, somite or epimeron (as appropriate) (Bradbury and Williams, 
1997). Mandibular palp setae are described using the notation of Karaman (1969) and Barnard and Barnard (1983). WAM: Western Australian Museum. BES: Field numbers of the biospeleology collection at WAM.

\section{Results}

Collection sites, positions and collectors are shown in Appendix 1. The majority of locations yielded few - in many cases single - specimens, many of which were immature or damaged, making unequivocal identification impossible. Three new species were detected, each from sites yielding relatively high numbers, and in each case, sympatric; Nedsia chevronia sp. nov. with $N$. hurlberti Bradbury and Williams, and the other case sympatry between Nedsia halletti sp. nov. and Nedsia stefania sp. nov.

Although specimens were in many cases damaged or immature, the following described species were identified among the collection: Nedsia hurlberti, collections 3395, 3397; N. humphreysi, collection 6969; N. straskraba, collections $3407,3420,3439 ; N$. sculptilis / $N$. macrosculptilis, 6980, 6983, 6984, 6990, 7001. Sample 7308 , a single small specimen, is probably of a new species. New species are described from samples $3424,3441,3462$.

\section{SYSTEMATICS}

\section{Family Melitidae Bousfield, 1973}

\section{Nedsia chevronia sp. nov.}

Figures 1-3

\section{Type locality}

Underground water, MW15, Barrow Island,

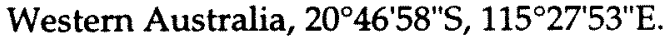

\section{Material examined}

\section{Holotype}

ð, ' $a$ ', 4 mm (WAMC 28207) Western Australian Museum field collection number BES 3424, $20^{\circ} 46^{\prime} 58^{\prime \prime S}$, $115^{\circ} 27^{\prime} 53^{\prime \prime E}, 23$ October 1998, W. F. Humphreys and S. M. Eberhard.

\section{Paratypes \\ $\delta$ ' $\mathrm{b}^{\prime}, 3.5 \mathrm{~mm}$ (WAMC 28208) 3 other $\delta$ o $2.5-3.0$ $\mathrm{mm}$ (WAMC 28311). Same data as holotype.}

\section{Other material}

17 specimens, all small, all damaged (WAMC 28312), Barrow Island, Western Australia, Western Australian Museum field collection number BES $3395,20^{\circ} 46^{\prime} 58^{\prime \prime} \mathrm{S}, 115^{\circ} 27^{\prime} 53^{\prime \prime} \mathrm{E}, 22$ October 1998, W.F. Humphreys and S.M. Eberhard.

\section{Diagnosis}

Pleonites with few dorsal setae. Head: rostrum obsolescent; lateral cephalic lobes moderately projecting, very broad; no antennal sinus present; eyes absent. First antenna: longer than A2; ratio of peduncular articles from 7:6:3; accessory flagellum 2 articulate. Second antenna: short; flagellum much shorter than peduncle; calceoli absent. Mandible: palp reduced, 2 articulate; ratio of mandibular palp articles $1: 1$, article 1 not setose, terminal article tapered, sub-truncate; setae 2 E. Upper lip: symmetrical. Lower lip: with inner lobes. Mandibles: 4 accessory blades (rakers), with inter-raker plumose setae between each main raker. Maxillae: moderately setose medially; inner plate of maxilla 1 ovate with 5 medial setae, outer plate with denticulate setae, palps symmetric, with thin apical setae; inner plate of maxilla 2 with row of medial setae extending onto face apically, other medial setae few. Maxilliped: outer plate with no blunt naked tooth setae continuous with distal plumose setae, palp article 3 apex not produced, dactyl with moderate length nail. Coxae: short, broader than long, with few posterior setae. Gnathopods diverse. First Gnathopod: palm transverse; setae at corner of palm = lateral 2 long, medial 4 short. Second Gnathopod: propodus palm defining corner with 2 setae laterally. Pleopods: similar; rami extending equally, basomedial setae of inner rami bifid; retinaculae 2, no accessory retinaculum present. Epimera: postero-ventral tooth of epimera 1-3 absent; posterior margins smooth; E2-3 bearing facial setae near ventral margin. Uropods: apicolateral corner of peduncles on uropods 1-2 with 2 setae; dorsal margins with setae; rami of uropods with no or one setal rows; outer ramus of uropod 3 with distal peduncular setae; inner ramus reaching to M0.17 on article 1 of outer ramus. Telson: cleft $100 \%$; single lateral penicillate setules at M0.6 on each side.

\section{Description of holotype (male " $a$ ")}

Body (Figure 1): $4 \mathrm{~mm}$. Urosome: poorly armed dorsally. Head: bearing few slender setae dorsally; rostrum obsolescent; eyes absent. First antenna (Figure 1): length $0.6 \times$ body, 2.4x A2; flagellum longer than peduncle; peduncular article 3 shortest, article 1 longest, ratio of lengths $=22: 18: 9$; setae sparse; flagellum of 18 articles; aesthetascs present on articles 3-15; calceoli absent; accessory flagellum 2 articulate, reaching M0.6 of article 1 of primary flagellum, article 2 tiny; articles of primary flagellum sub-uniform, sparsely setulate. Second antenna (Figure 1): length $0.25 x$ body; peduncle much longer than flagellum, article 4 longer than 5 , 3-5 with weak ventral setation; flagellum 4 articulate, the apical article bearing a small aesthetasc. Upper lip: margin not excavate. Mandibles (Figure 1): left mandibular palp 2 articulate, short, 


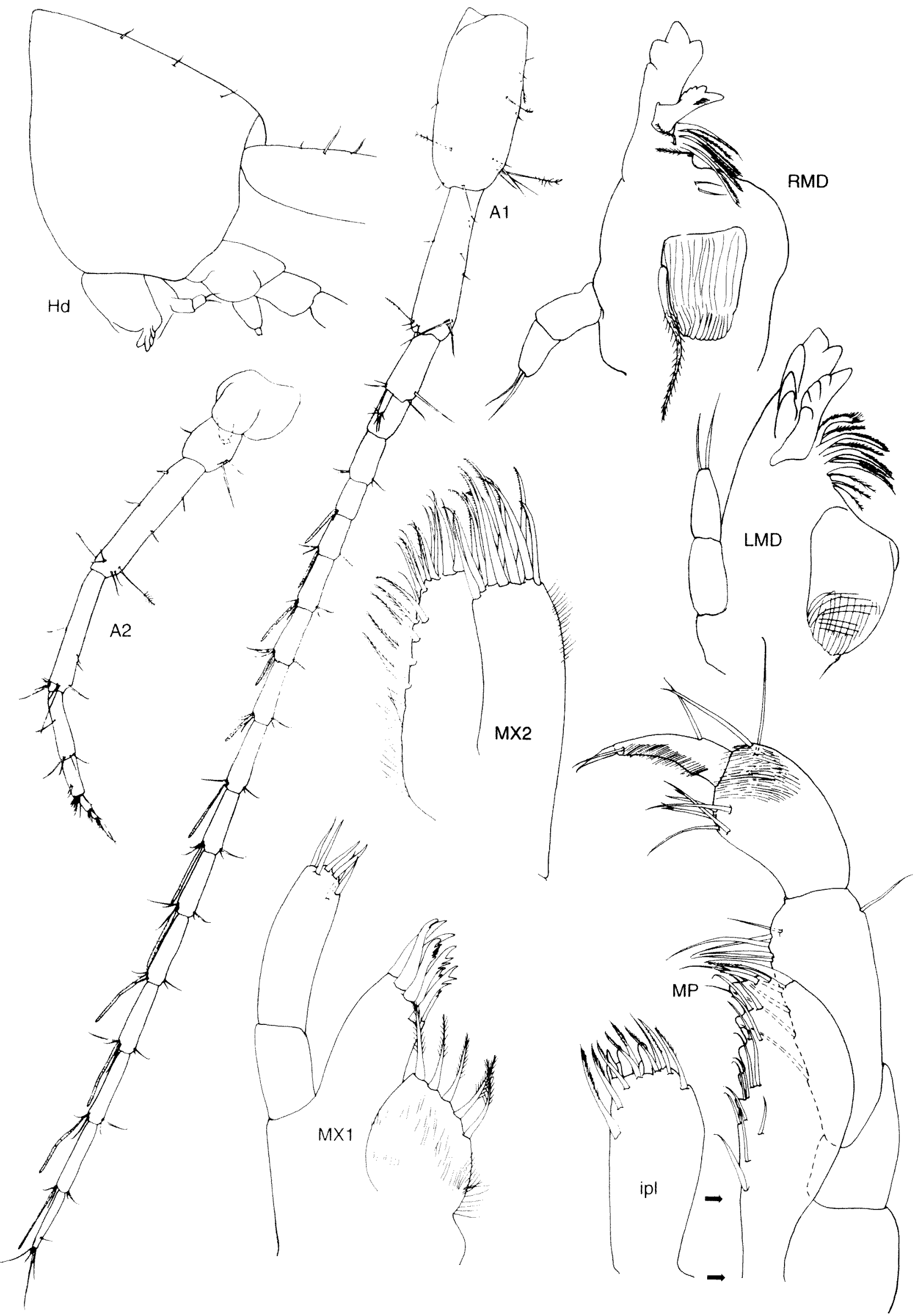

Figure 1 Nedsia chevronia sp. nov. Holotype, male 'a' $4 \mathrm{~mm}$. Head, antennae, mandible, maxillae and maxilliped. 


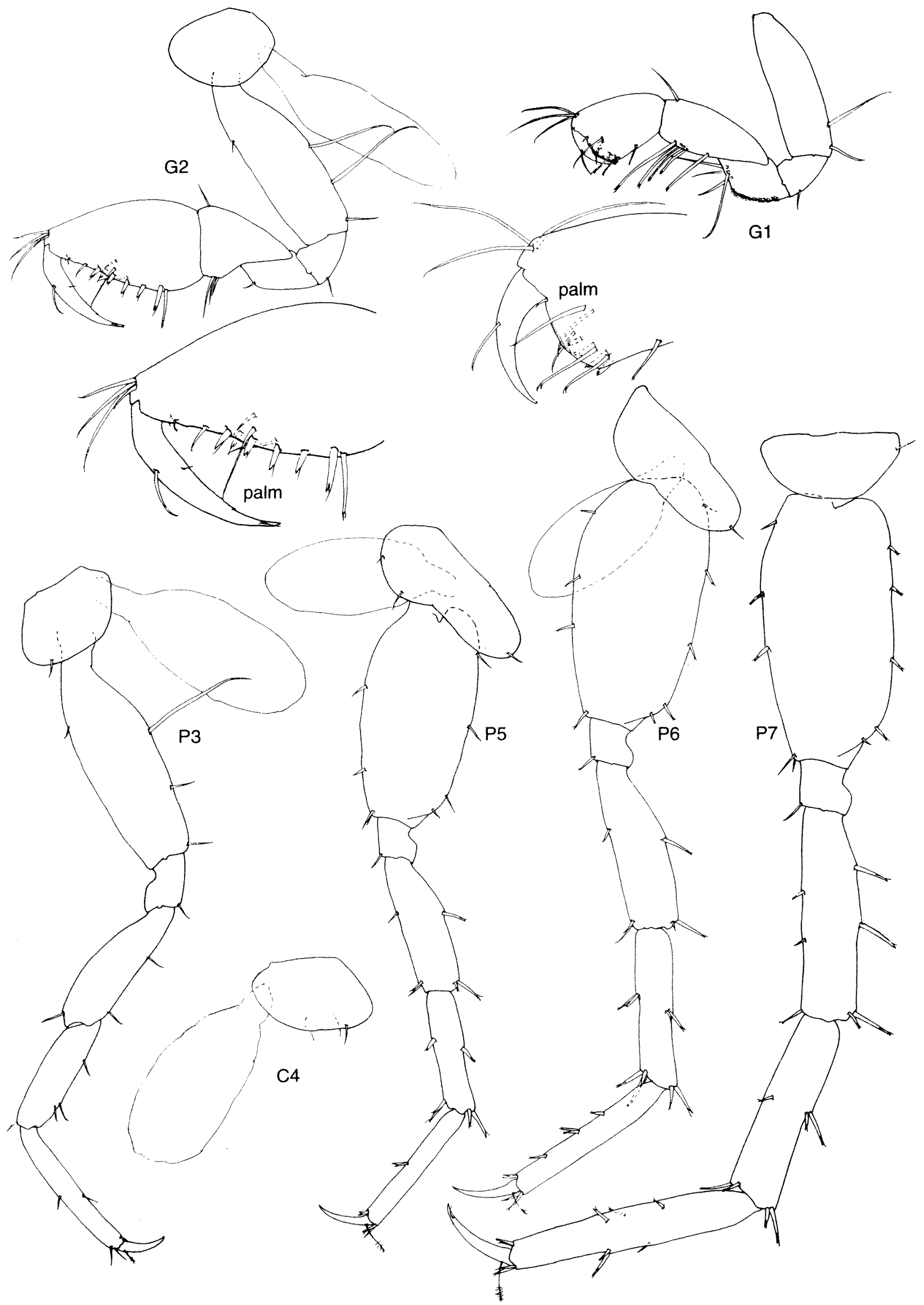

Figure 2 Nedsia chevronia sp. nov. Holotype, male 'a' 4 mm. Gnathopods, gnathopodal palms, pereopods3, 5-7. 
articles equal in length, article 2 with 2 long apical $E$ setae; incisor 5 toothed; lacinia mobilis with 5 denticles; 4 setose accessory blades and plumose inter-raker setae; molar without distal plumose seta, triturative, a few small setae basal to the molar; right mandibular incisor 4 toothed; lacinia mobilis barely bifid, broad, finely denticulate anteriorly; accessory blades of 4 plumose setae with few interraker plumose setae; molar triturative, bearing a long distal plumose seta; palp 2 articulate, articles of approximately equal length, the distal article tapering, bearing 2 E setae. First maxilla (Figure 1): palp article 2 with 6 thin apical setae, all naked; outer plate with 7 denticulate setae; inner plate bearing 5 medio-distal to terminal plumose setae, medial margin and face pubescent. Second maxilla (Figure 1): outer plate disto-laterally pubescent; inner plate pubescent on baso-medial margin, bearing medio-marginal to disto-facial row of 5 plumose setae. Maxilliped (Figure 1): nail of palp moderately long, dactyl bearing also accessory distal seta as long as the nail, facially bearing fine setae, apex of article 3 not produced, with few thin setae basal to the dactyl, none proximal; inner plate with a disto-facial row of 4 plumose setae, 3 apical naked tooth setae and 4 rastellate or naked setae; outer plate bearing 5 medio-marginal indentations and a row of 11 terminally hooked long slender setae, mostly arranged in pairs. First gnathopod (Figure 2): (coxal plate without anterior setae, naked posteriorly); article 4 slightly bulbous posteriorly, bearing short, fine setae; carpus elongate, not lobate; propodus trapezoidal, expanding slightly apically, longer than wide, the posterior edge naked, corner of palm rounded, bearing 2 long, naked lateral setae, and a row of 4 stout bifid setae medially as well as a long slender naked seta, palm slightly convex, dactyl reaching to the palmar corner. Second gnathopod (Figure 2): coxa bearing no setae, carpus subtriangular, short; propodus ovate, elongate, naked dorsally, the palmar corner with no medial and 2 lateral setae - one long, slender, apically bifid, the other robust and apically bifid; marginally 4 other stout trigger setae, a single slender seta and small seta basal to the dactyl as well as a long naked slender sub-marginal seta along the lateral palm; medial palm bearing a single robust trigger seta, 2 sub-marginal long slender setae and small seta basal to the dactyl. Pereopods (Figure 2): coxa 3 with a single anterior seta; coxa 4 bearing single anterior and posterior setae; P3-(4) longer than G2; P3-5 approximately equal, articles 4,5 sparsely setose posteriorly, propodi of $\mathrm{P} 3-4$ bearing single locking setae; P6-7 longer; P5-7 similar but consecutively elongate, each with 2 locking setae; P7 anterior setae of article 6 displaced inward by keel-like expansion of the segment; coxae 5-7 bearing 1,1,1 setae on posterior lobes and 2,0,0 anterior setae; article 2 weakly expanded, greatest on P6, of P7 longest, none lobate, but extended posteriorly, bearing few setae; dactyls of P3-7 simple, naked except for an anterior basal penicillate setule, with the addition of an outer terminal seta accessory to the nail on P7. Gills: coxae 2-6 with flask shaped gills, gill of C3 largest, of C5-6 slightly reduced. Pleopods (Figure 3 ): retinaculae 2 per pleopod, no accessory retinaculae; peduncles without apico-lateral setae; rami extending equally, the inner with 5:5:4 articles, the outer with $6: 6: 6$; a single bifid seta on the inner basal articles. Epimera (Figure 3): epimera 1-2 postero-ventrally rounded, of E3 sub-quadrate; posterior margin of E1 sinuous, of E2 straight, of E3 barely convex, all smooth, with no setae except a single seta each marking the postero-ventral corner; E2-3 with 1 and 3 ventral setae, lacking lateral oblique ridge. Pleon (Figure 3): pleonites $1-6$ with few dorso-lateral posterior setae; pleonite 6 with 1 dorso-lateral seta, but without any disto-ventral spinule. Uropods (Figure 3): uropod lengths relative to $\mathrm{U} 1$ are $\mathrm{U} 2=0.6 \mathrm{x}, \mathrm{U} 3=1.6 \mathrm{x}$; $\mathrm{U} 1$ peduncle length $1.5 \mathrm{x}$ inner ramus, the outer margin bearing a pair of apico-distal setae and reduced row of 2 mid-dorsal setae, the medial apex bearing 2 setae, the medial margin with 2 setae; rami of sub-equal length, both naked except for a single medial mid-dorsal seta on the inner ramus; both rami with 4 terminal setae; $\mathrm{U} 2$ peduncle length $0.9 \mathrm{x}$ inner ramus, bearing 2 apico-lateral and apico-medial setae; inner ramus length $1.5 x$ outer, the medial margin bearing 2 setae only, 5 terminal setae; outer ramus shorter, bearing a single mid-lateral seta and 4 apical setae; U3 strongly extended beyond uropods $1-2$ in entire animal; peduncle length $0.5 x$ outer ramus, shorter than urosomite 3 , bearing single mid-dorsal and paired latero-distal marginal setae; outer ramus proximal article with few marginal setae, 4 apicomedial setae, 2 apico-lateral setae and 2 dorsal setae; article 2 shorter $(0.9 x)$, similarly armed but bearing fine short distal setules medially and laterally, terminating in a cluster of 6 slender setae; inner ramus scale like, sub-quadrate, length $0.14 x$ outer, bearing a single apico-medial seta. Telson (Figure 3): length $1.3 x$ width, widest at base, subequal in length to urosomite 3 , cleft $100 \%$; apices slightly notched laterally; sub-apices with a long plumose seta, 1 sub-distal medial seta and 1 lateral seta at M0.8, no other dorsal setae except for single penicillate setules on both lobes laterally at M0.6.

\section{Description of other material}

Specimen ' $b$ ', male: length $3.5 \mathrm{~mm}$. Pleonite 6 with a single dorso-lateral seta posteriorly. First antenna: flagellum of 11 articles, aesthetascs present on articles 5,7,9,10. Mandibles: setae of terminal article $=2 \mathrm{E}$; interraker plumose setae present between accessory blades. Maxilliped: palp article 3 with 6 slender setae basal to dactyl; nail of dactyl moderately long, bearing 2 slender 


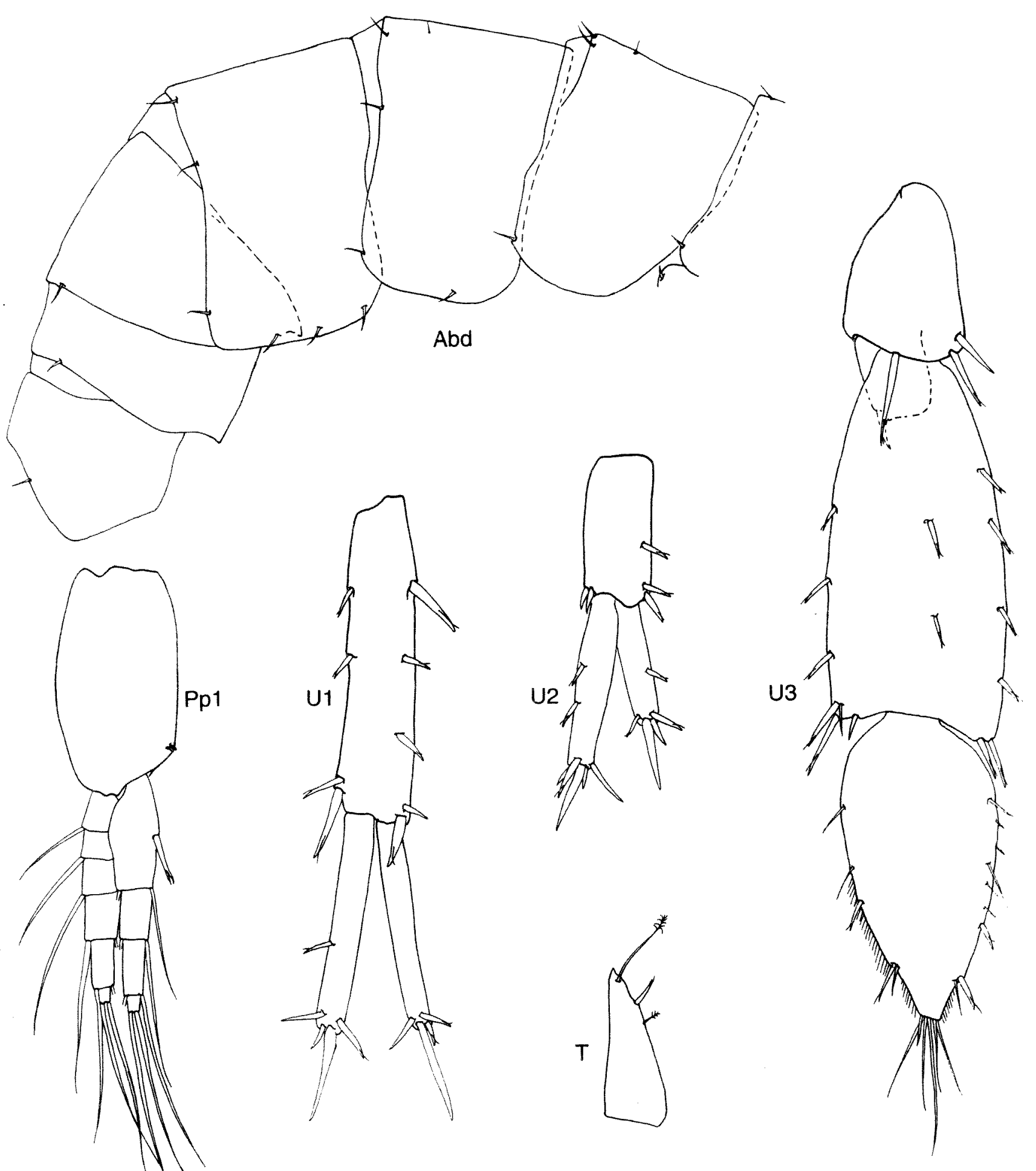

Figure 3 Nedsia chevronia sp. nov. All illustrations holotype, male 'a' 4 mm., except where indicated. Abdomen, pleopod 1, uropods and telson. Female allotype ' $b$ ' $4 \mathrm{~mm}$. telson.

accessory nails extending slightly beyond the nail. Coxae 1-3 bearing single apical and facial posterior setae; coxa 4 without anterior seta, with facial posterior seta, coxa 5 with single anterior and posterior setae, coxae 6-7 bearing single posterior setae only. Pleopods: accessory setae absent; inner rami of 4:4:4 articles, outer rami of
5:4:4 articles. Uropod: lengths relative to $\mathrm{U} 1 ; \mathrm{U} 2$ $0.6 \mathrm{x}$, U3 1.6x; peduncle of $U 11.1 \mathrm{x}$ length of inner ramus, of $\mathrm{U} 20.7 \mathrm{x}$; $\mathrm{U} 2$ inner ramus $2 \mathrm{x}$ outer; peduncle of U3 $0.28 \mathrm{x}$ length of outer ramus, second article of outer ramus equal in length to first; inner ramus $0.1 \times$ outer. Telson: bearing single slender plumose setae subapically. 


\section{Distribution}

Underground water, MW15/SB36 (field collection number BES3424), bore adjacent the tank farm, Barrow Island oilfields, altitude $9.0 \mathrm{~m}$ AHD, on coastal flats, $65 \mathrm{~m}$ from coastal cliffs, depth to water surface $9.0 \mathrm{~m}$, the limestone cavernous immediately above and below the water table.

Barrow Island, Western Australia, 20 46 $58^{\prime \prime} \mathrm{S}$, $115^{\circ} 27^{\prime} 53^{\prime \prime} \mathrm{E}$

Sympatric with N. hurlberti: WAM; BES3395, 22 October 1998 (Table 1).

\section{Etymology}

Named for Chevron Australia Pty. Ltd., whose assistance enabled this study to be initiated.

\section{Relationships}

This species differs from all others of the genus in: the flagellum of the first antenna is of 15 articles; propodus of the first gnathopod bears 2 long , apically bifid slender setae adjacent the corner and 1 short seta basal to the dactyl laterally, and 4 stout robust apically bifid setae from the palmar corner to the mid palm laterally; the propodus of the second gnathopod bears 1 long slender apically bifid and 1 stout robust trigger seta adjacent the palmar corner as well as a row of 4 robust trigger setae and 3 slender setae along the palm laterally, without medial setae adjacent the palmar corner, but 2 long slender and 1 short robust trigger setae midway along the palm as well as a short slender seta basal to the dactyl. The second coxal plate lacks anterior setae; articles 5-6 of the seventh pereopod without a keel like expansion thus anterior setae not displaced inward; rami of pleopods 1-3 of 5,5,4 medial and 6,6,6 lateral articles.

The species also differs from others of the genus by: first antenna peduncle article 1 longest, unlike $N$. macrosculptilis and N. sculptilis, and aesthetascs are present on the flagellum whereas in $N$. humphreysi and $N$. urifimbriata they are absent; article 4 of the peduncle of the second antenna is longer than article 5, thus differing from all species except $N$. fragilis and the flagellum is 4 articles long, unlike $N$. urifimbriata, $N$. macrosculptilis and $N$. sculptilis. The second article of the mandibular palp lacks D setae, unlike $N$. straskraba; the incisor bears 5 teeth unlike $N$. hurlberti and the left lacinia bears 5 denticles unlike $N$. straskraba, N. hurlberti and $N$. humphreysi; the mandible bears 4 setose accessory blades, differing from $N$. halletti, $N$. straskraba, $N$. humphreysi, N. fragilis, N. macrosculptilis and $N$. sculptilis and, unlike $N$. sculptilis and $N$. fragilis, bears no other pubescence. The palp of the first maxilla bears 6 slender setae apically similar only to $N$. urifimbriata, N. hurlberti and N. sculptilis, and the inner plate bears 5 disto-medial plumose setae, unlike all but $N$. halletti; the outer plate of the second maxilla pubescent, unlike $N$. stefania, $N$. straskraba, N. humphreysi and N. fragilis. Coxa 2 without posterior setae, unlike $N$. straskraba, N. fragilis and $N$. macrosculptilis; coxa 3 with 2 anterior setae, differing from $N$. halletti, N. stefania, $N$. hurlberti and $N$. macrosculptilis, and no posterior setae, unlike $N$. straskraba, N. humphreysi and $N$. fragilis; coxa 4 bears 1 anterior seta and no posterior setae, thus differing from $N$. macrosculptilis, $N$. sculptilis, N. hurlberti, N. humphreysi and $N$. urifimbriata. Pereopods 5-7: coxae with 1 posterior seta, differing from $N$. stefania and $N$. straskraba, articles 2 weakly expanded progressively, unlike $N$. stefania, and propodi bear paired locking setae, unlike $N$. straskraba. Pleopods without accessory retinaculae, unlike $N$. straskraba; epimera posteroventrally rounded, differing from $N$. sculptilis, $N$. straskraba, N. hurlberti, N. urifimbriata, N. fragilis and N. macrosculptilis. First and second uropod rami with 4 apical setae unlike $N$. halletti, $N$. stefania, $N$. straskraba, N. fragilis, N. hurlberti and N. humphreysi; third uropod peduncle relatively longer than in $N$. fragilis and $N$. macrosculptilis, and bearing a single mid dorsal seta unlike $N$. halletti, and 2 laterodistal marginal setae and 1 sub apical lateral seta unlike $N$. straskraba and $N$. urifimbriata; the outer ramus proximal article bearing 4 apico-medial and 2 apicolateral setae and the second article terminates in a cluster of 6 setae, unlike $N$. halletti, N. straskraba, N. urifimbriata and $N$. macrosculptilis; inner ramus bearing a single apico-medial seta, differing from $N$. halletti, N. urifimbriata and $N$. macrosculptilis. The telson relatively longer than all but $N$. sculptilis; cleft $100 \%$ unlike N. sculptilis; the lobes without submarginal medial setae, unlike $N$. sculptilis, $N$. straskraba, N. hurlberti, N. urifimbriata and $N$. macrosculptilis; bearing single lateral penicillate setae at M0.5, more basal than in $N$. halletti and $N$. urifimbriata.

\section{Nedsia stefania sp. nov. Figures 4-6}

\section{Type locality}

Underground water in L32J old water well, Barrow Island, Western Australia, 20 $48^{\prime} 34 S^{\prime \prime}$, $115^{\circ} 22^{\prime} 42^{\prime \prime} \mathrm{E}$

\section{Material examined}

\section{Holotype}

§. ' $a$ ' 4 mm (WAMC 28343) Western Australian Museum field collection number BES 3441, L32J, old water well, $20^{\circ} 48^{\prime} 34 S^{\prime \prime}, 115^{\circ} 22^{\prime} 42^{\prime \prime} \mathrm{E}, 24$ October 1998, W.F. Humphreys and S.M. Eberhard.

\section{Paratypes}

$\delta$. ' $b$ ' $2 \mathrm{~mm}, 2$ other, incomplete specimens (WAMC 28344). Same data as holotype. 


\section{Diagnosis}

Pleonites with few dorsal setae. Head: rostrum obsolescent; lateral cephalic lobes moderately to strongly projecting, very broad; no antennal sinus present; eyes absent. First antenna: longer than A2; ratio of peduncular articles 2.5:2.5:1. Second antenna: short. Upper lip: symmetrical; not excavate below. Mandible: 3 accessory blades with interraker plumose setae between each main raker; palp 2 articulate, length ratio of articles 1:1, terminal article tapered, setae 2 E. Maxillae: moderately setose medially; inner plate of maxilla 1 with 2 (3) medial setae; inner plate of maxilla 2 with row of medial setae extending onto face apically, other medial setae few. Maxilliped: inner plate very long with distal row of 2 plumose setae and 3 blunt naked setae; outer plate large, with 3 distal setae, without a blunt naked tooth seta; medial margin carved into sinuosities, spineless; sub-marginal face with pairs of setae; palp articles 2-3 weakly setose laterally, article 2 moderately setose medially, article 3 with setae or comb rows of setae near the base of the dactyl, apex not produced, dactyl unguiform, with moderate length nail. Gnathopods 1-2 diverse: first gnathopod some setae simple, some bearing trigger hairs and thus asymmetrically bifid, some apically dentate; setae at corner of palm = lateral 1 long trigger, medial 2 robust bifid and 2 slender simple; setae along palm sparse and simple; second gnathopod defining corner with 2 setae. Coxae 1-7: with few posterior setae. Pleopods: similar; rami extending sub-equally, basomedial setae of inner rami bifid; retinaculae 2 , no accessory retinaculum present. Epimera: postero-ventral tooth of epimera 1-3 absent; posterior margins smooth and sparsely setulose; some bearing facial setae near ventral margin. Pleon: ventro-distal seta on urosomite 1 at base of uropod 1 absent. Uropods: apico-lateral corner of peduncles on uropods 1-2 with 2 and 1 setae, dorsal margins with few setae; medial margin of uropod 1 with 2 apical setae; rami of uropods 1 and 2 extending sub-equally; uropod 1 with basofacial seta; rami of uropods 1-2 with few setae. Telson: longer than broad; cleft $100 \%$; lobes weakly convex laterally, with sub-apical plumose setation; lateral setae present.

\section{Description of holotype (male ' $a$ ')}

Body (Figure 4): $4 \mathrm{~mm}$. Urosome: poorly armed dorsally. Head: bearing few dorsal setules, rostrum obsolescent; eyes absent. First antenna (Figure 4): length $0.4 \mathrm{x}$ body, 1.7x A2; flagellum longer than peduncle; peduncular article 3 shortest, article 1 longest, ratio of lengths $=2.3: 2: 1$, setae sparse; aesthetascs present on articles 5-7; calceoli absent; flagellum of 8 articles; accessory flagellum 2 articulate, reaching M0.7 of article 1 of primary flagellum, article 2 tiny; articles of primary flagellum not uniform, sparsely setulate. Second antenna (Figure 4 ): length $0.2 x$ body; peduncle much longer than flagellum, article 5 longest, 3-5 with weak ventral setation; flagellum 4 articulate, without calceoli. Upper lip: margin not excavate. Mandibles (Figure 4): left mandibular palp reduced, 2 articulate, articles sub-equal in length, article 2 with 2 long apical $E$ setae; incisor 6 toothed; lacinia mobilis with 5 denticles; 4 setose accessory blades and inter-raker plumose setae; molar without distal pappose seta, triturative; no other pubescence; right mandibular incisor 4 toothed; lacinia mobilis bifid, broad, finely denticulate; accessory blades of 3 plumose setae and plumose inter-raker setae; palp 2 articulate, molar triturative, bearing a long distal pappose seta. First maxilla (Figure 4): palp article 2 with 5 thin apical setae, all naked; outer plate with 7 denticulate setae; inner plate bearing 2 apicomedial plumose setae, medial margin naked. Second maxilla (Figure 4): outer plate devoid of pubescence; inner plate pubescent on baso-medial margin. Maxilliped (Figure 4): nail of palp moderately long, medial margin of article 3 with 5 distal thin setae basal to the dactyl, none proximal; inner plate with a row of 3 medial marginal to facial setae, three naked tooth setae and 5 rastellate or naked setae apically; outer plate medial margin bearing 3 deep and one shallow indentations, a single mid marginal seta and a row of 7 mainly paired long naked apically hooked setae adjacent the indentations. First gnathopod (Figure 5): coxal plate with a single short seta apically and none posteroventrally; article 4 slightly bulbous and setate posteriorly; carpus not lobate, longer than wide; propodus trapezoidal, expanding slightly apically, longer than wide, the posterior edge naked, corner of palm rounded, bearing 1 long, naked, apically bifid lateral seta, 2 stout bifid setae and one slender seta medially, palm slightly convex, dactyl reaching slightly beyond the palmar corner. Second gnathopod (Figure 5): coxa bearing a single apical seta; propodus ovate, palmar angle acute, palmar corner bearing 2 lateral setae - one long, slender and apically bifid, the other a robust trigger seta -, the mid palm bearing a single slender seta and short seta basal to the dactyl laterally, and medially a slender and a short robust setae. Pereopods (Figure $5)$ : coxa 3 without setae, as long as wide, coxa 4 bearing an anterior seta; P3-4 longer than G2; P3(5) approximately equal, all articles sparsely setose, propodus with only one locking seta; $P(5)-7$ similar but consecutively elongate, with (2),2,2 locking setae; P6 anterior seta of articles 5 and 6 displaced inward by keel-like expansion of the segment; coxae 5-7 bearing 1,0,1 setae on posterior lobes, P6-7 articles 2 weakly expanded, subequally, not lobate; dactyls of P3-7 simple, naked except for an anterior basal penicillate setule, with the addition of an outer terminal setule on P6-7. Gills: coxae 2-6 with flask shaped gills. Pleopods (Figure 6): retinaculae 2 


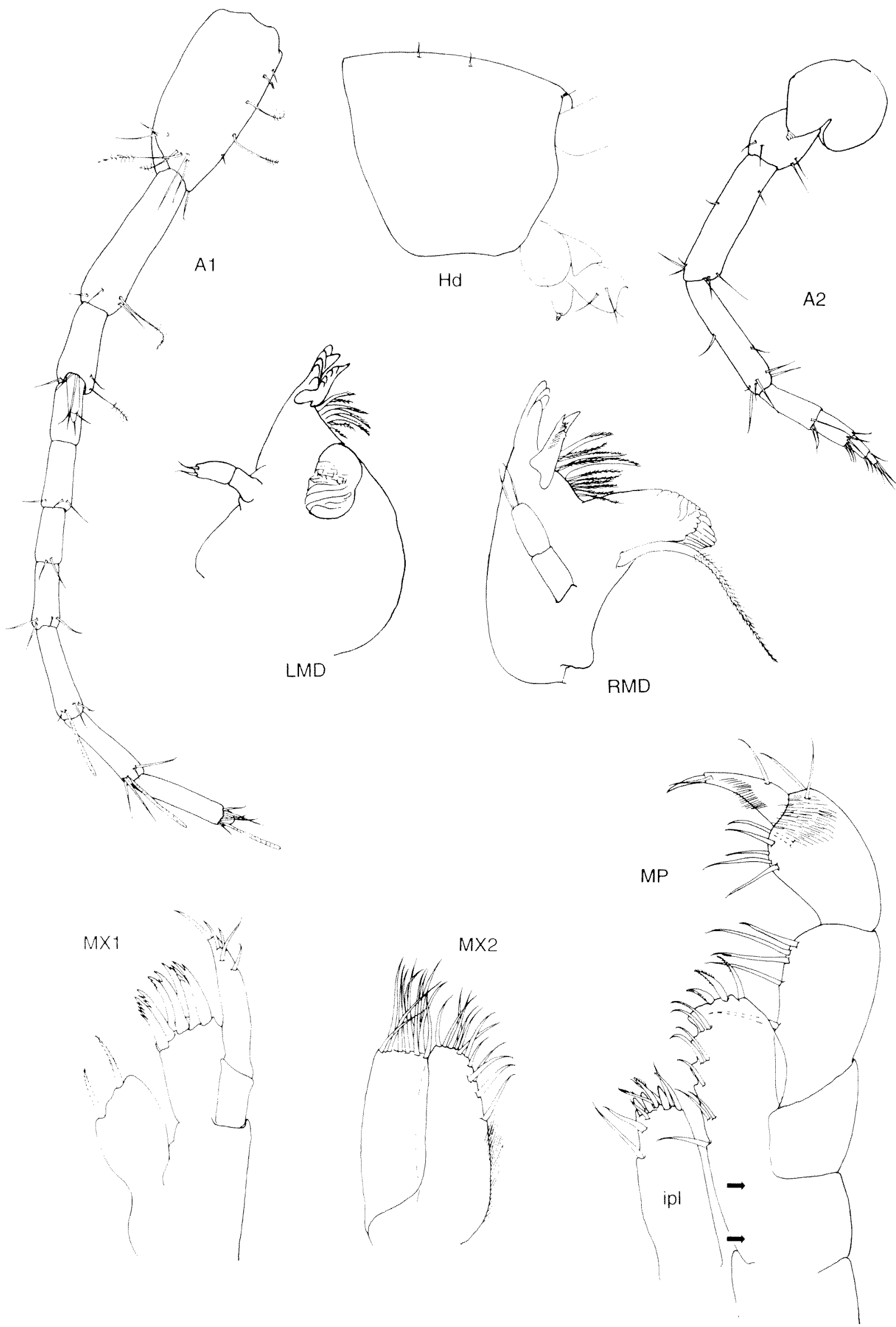

Figure 4 Nedsia stefania sp. nov. Holotype, male $4 \mathrm{~mm}$. Head, antennae, mandibles, maxillae and maxilliped. 

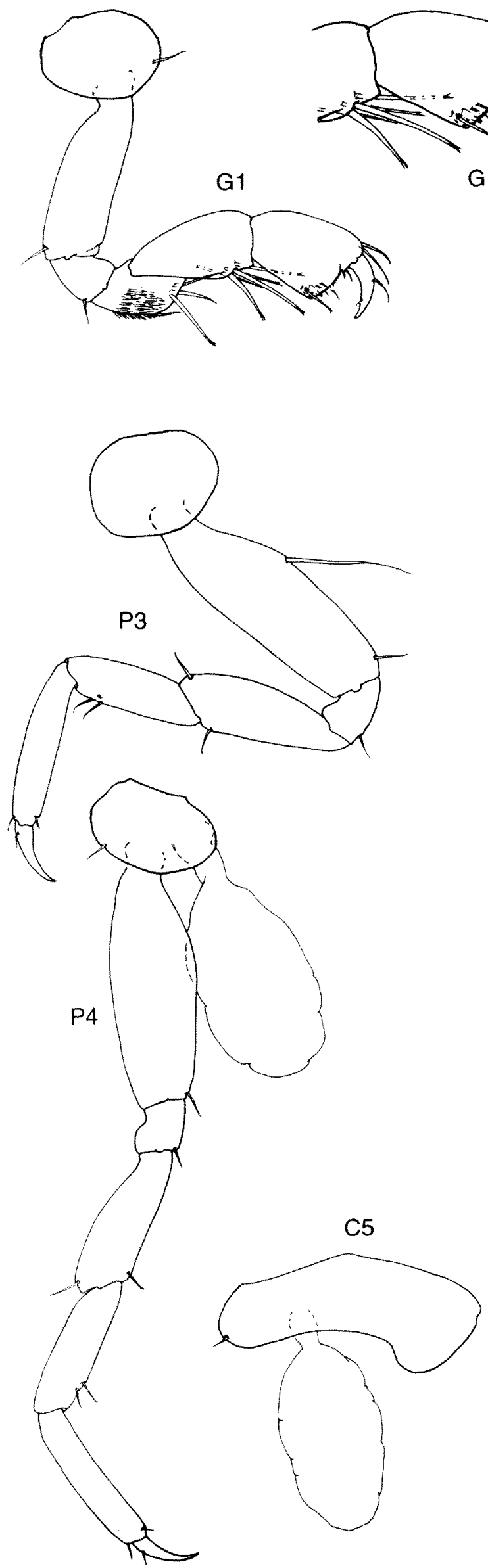

G1
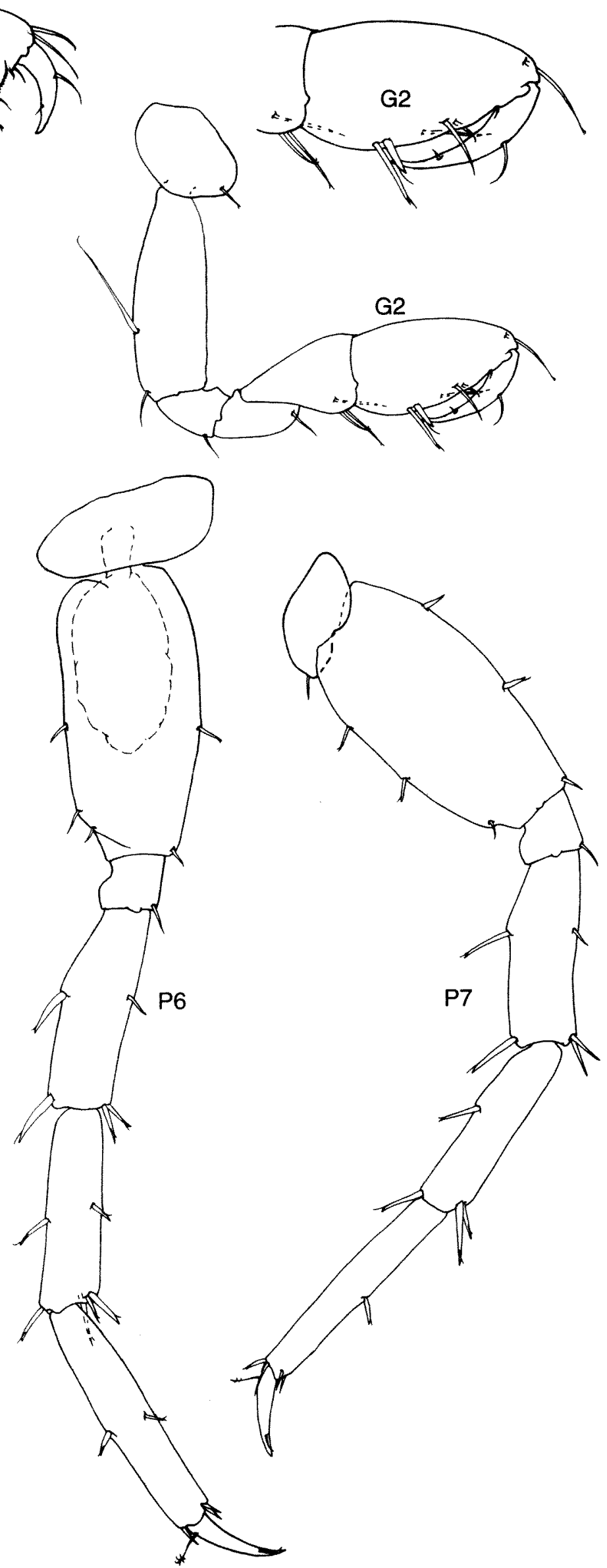

Figure 5 Nedsia stefania sp. nov. Holotype, male $4 \mathrm{~mm}$. Gnathopods, gnathopodal palms, coxa 4, pereopods 3,5-7. 


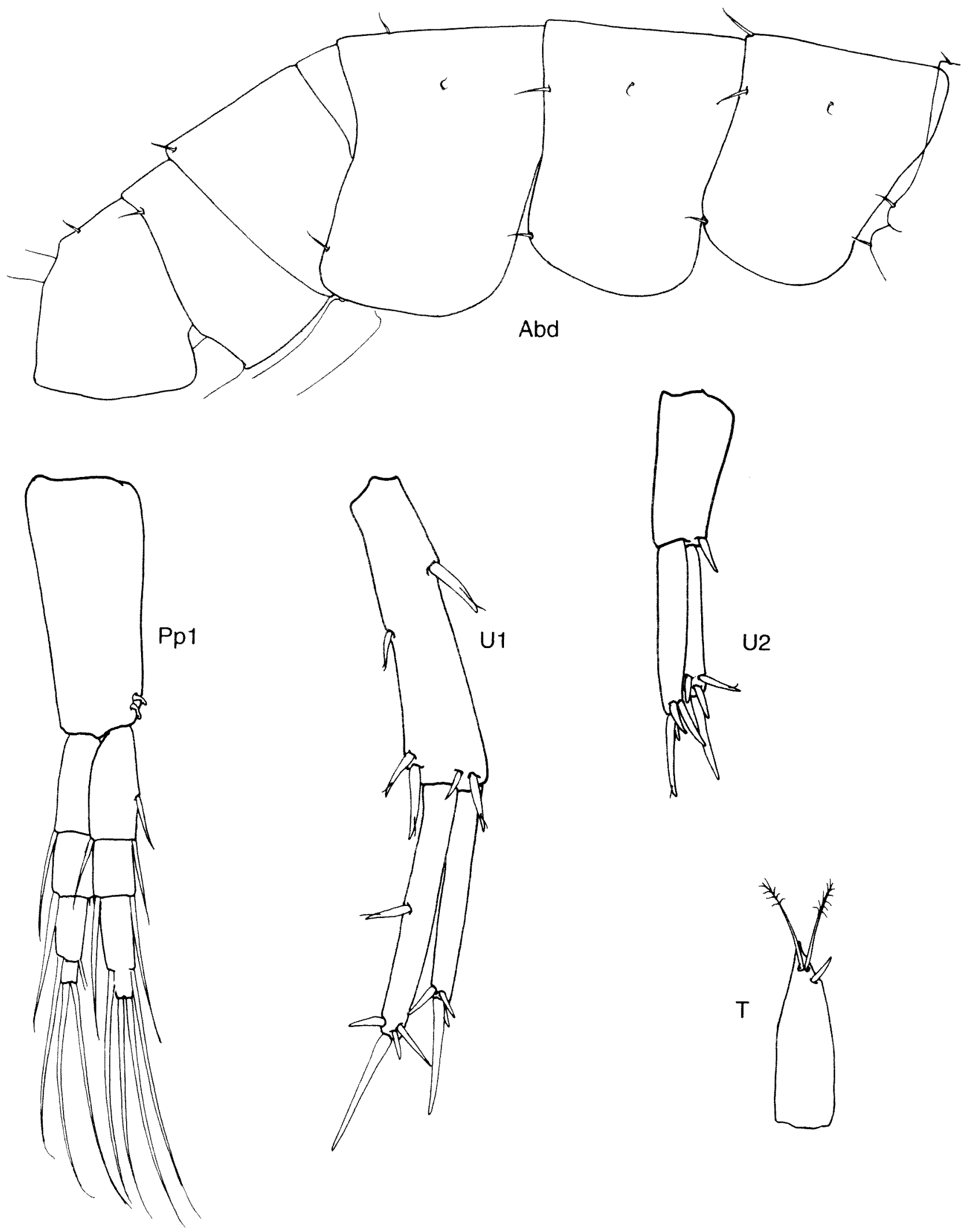

Figure 6 Nedsia stefania sp. nov. Holotype, male $4 \mathrm{~mm}$. Abdomen, pleopod 1, uropods and telson.

per pleopod, no accessory retinaculae; peduncles without other setae; rami extending sub-equally, the inner with 4:4:4 articles, the outer with 4:4:4articles; no bifid setae on basal articles. Epimera (Figure 6): epimera postero-ventrally rounded; posterior margins scarcely convex on 1-2, slightly concave on E3, all smooth, with few or no setae; ventral setae lacking, each with a single, slender postero-ventral 
seta marking the posterior corner. Pleon (Figure 6): pleonites 1, 3 and 6 bearing dorsal setae, 1, 2, 4 and 5 with dorso-lateral posterior setae. Uropods (Figure 6): length of $U 2$ relative to $U 1=0.6 x$; $U 1$ peduncle length $1.2 \mathrm{x}$ inner ramus, the outer margin bearing two apico-distal setae and no mid-dorsal setae, the medial apex bearing 2 setae, the medial margin bearing a single short robust seta; rami of sub-equal length (inner : outer $=62: 52$ ), both naked except for a single mid-dorsal seta on the inner ramus; both rami with 4 terminal setae; U2 peduncle length $0.8 x$ inner ramus, bearing a single apico-lateral seta only; inner ramus length $1.2 x$ outer, the medial margin without setae, 4 terminal setae; outer ramus shorter, also devoid of any but 4 terminal setae; (U3 strongly extended beyond uropods $1-2$ in entire animal; inner ramus scale like, sub-quadrate). Telson (Figure 6): length $1.5 x$ width, widest at base, sub-equal in length to urosomite 3 , cleft $100 \%$; apices slightly notched laterally; sub-apices with 2 long plumose setae, 1 sub-marginal disto-medial seta.

\section{Description of other material}

Specimen ' $\mathrm{b}$ ', male: length $2 \mathrm{~mm}$. F'eonite 6: without a dorso-lateral seta. First antenna: flagellum (broken), aesthetascs present on articles 3,5. Mandibles: ratio of length of palp articles $1-2=5: 4$; setae of terminal article $=2 \mathrm{E}$; interraker plumose setae present between accessory blades. Maxilliped: palp article 3 with rows of setae basal to dactyl; nail of dactyl short. First gnathopod: coxal plate with single anterior seta and facial posterior seta. Pleopods: accessory setae absent. Uropods: lengths relative to U1; U2 $0.6 \mathrm{x}$, peduncle of $\mathrm{U} 11.3 \mathrm{x}$ length of inner ramus, of U2 $0.8 x$ inner ramus; $\mathrm{U} 2$ inner ramus $1.3 \mathrm{x}$ outer. Telson bearing a single subapical seta on either lobe.

\section{Distribution}

Underground water in L32J old water well (field collection BES3441); disused, steel cased water bore at altitude $50 \mathrm{~m}$ above $\mathrm{AHD}$, in the central heights, Barrow Island, ground-water $2 \mathrm{~m}$ deep at about sea level.

Barrow Island, Western Australia, 2048'34S", $115^{\circ} 22^{\prime} 42^{\prime \prime} \mathrm{E}$

\section{Etymology}

Named for Stefan Fritz, who facilitated collecting visits to Barrow Island.

\section{Relationships}

This species differs from all others in that: the flagellum of the first antenna is of 8 articles; right mandible bears 3 accessory blades; the first maxilla inner plate bears 2 setae medially. The first gnathopod propodus palm bears a single long lateral trigger seta at the corner and only one other lateral seta basal to the dactyl; the medial corner of the palm bears 2 robust apically bifid and 2 slender simple setae and the palm only one other seta basal to the dactyl. The second gnathopod propodus lateral corner is marked by a long slender trigger seta, and the lateral palm bears 1 mid-marginal slender seta and a small seta basal to the dactyl; medial palm bearing 2 slender simple setae mid way along the palm. Pereopod 2 coxa without an anterior seta. Telson lacking lateral penicillate setules.

Other differences: lacking serration of the pleon and the first article of the first antennal peduncle the longest, unlike $N$. macrosculptilis and $N$. sculptilis; first antenna bearing aesthetascs, unlike $N$. humphreysi and $N$. urifimbriata; the first two articles of the flagellum of the first antenna not fused as in N. sculptilis and N. macrosculptilis; the second antenna flagellum of 4 articles, unlike $N$. urifimbriata, N. macrosculptilis and N. sculptilis; mandibular palp without $D$ setae as in N. straskraba, the incisor bearing 5 teeth unlike $N$. hurlberti and $N$. macrosculptilis and the mandible bearing 4 setose accessory blades, similar only to $N$. urifimbriata, $N$. douglasi and $N$. hurlberti, the mandible lacking other pubescence, unlike $N$. sculptilis and $N$. fragilis; the palp of the first maxilla bearing 5 slender apical setae, unlike $N$. sculptilis, N. macrosculptilis and $N$. hurlbert $i$; the outer plate of the second maxilla devoid of pubescence, differing from $N$. hurlberti, $N$. urifimbriata, N. macrosculptilis, N. sculptilis and $N$. halletti. First gnathopod coxa bearing 2 anterior and no posterior setae, similar only to $N$. halletti, $N$. chevronia and $N$. humphreysi; coxa of the second gnathopod bearing 2 anterior and no posterior setae, unlike $N$. straskraba, $N$. hurlberti, $N$. fragilis, $N$. macrosculptilis and $N$. douglasi. Pereopods 3-4 subequal in length unlike $N$. sculptilis; pereopods 5 and 7 with paired locking setae, not single as in $N$. straskraba, and coxae 5-7 bearing 1,0,1 posterior setae unlike $N$. hallett $i$ and $N$. straskraba, the second articles weakly expanding progressively posteriorly unlike $N$. halletti and not extending posteriorly unlike $N$. straskraba. Pleopods without accessory retinaculae, differing from $N$. humphreysi and $N$. straskraba; both rami of 4,4,4 articles, unlike all except $N$. halletti and $N$. fragilis. Uropod 1 peduncle bearing a reduced row of mid dorsal seta and the medial apex bearing 2 setae, differing from all other species; the rami subequal in length unlike $N$. fragilis and $N$. sculptilis; bearing a single mid dorsal seta medially unlike $N$. hurlberti and N. urifimbriata; both rami bearing 4 apical setae, differing from all but $N$. halletti, N. chevronia, $N$. fragilis and $N$. humphreysi. The second uropod peduncle approximately equal in length to the inner ramus, unlike $N$. halletti, $N$. chevronia, $N$. urifimbriata, $N$. fragilis and $N$. macrosculptilis; bearing a single apicolateral seta unlike $N$. sculptilis and $N$. hurlberti; the 
inner ramus medial margin naked unlike $N$. halletti, $N$. chevronia, $N$. sculptilis, $N$. straskraba, N. hurlberti and $N$. urifimbriata; both rami bearing 4 apical setae, unlike $N$. chevronia, $N$. straskraba and $N$. hurlberti. The telson shorter than $N$. halletti, N. macrosculptilis and N. humphreysi; cleft $100 \%$, unlike N. sculptilis; and lacking submarginal medial setae, differing from N. sculptilis, N. straskraba, N. hurlberti, N. urifimbriata and $N$. macrosculptilis.

\section{Nedsia halletti sp. nov.}

Figures 7-10

\section{Type locality}

Underground water in L32J old water well, Barrow Island, Western Australia, 20 48 $34^{\prime \prime} \mathrm{S}$, $115^{\circ} 22^{\prime} 42^{\prime \prime} \mathrm{E}$

\section{Material examined}

\section{Holotype}

o. ' $a$ ' $4 \mathrm{~mm}$ (WAMC 28345) Western Australian Museum field collection number BES 3462, L32J, old water well, $20^{\circ} 48^{\prime} 34 S^{\prime \prime}, 115^{\circ} 22^{\prime} 42^{\prime \prime} \mathrm{E}, 25$ October 1998, W.F. Humphreys and S.M. Eberhard.

\section{Allotype}

$\delta$, 'b', $4 \mathrm{~mm}$ (28346). Same data as holotype.

\section{Paratype}

б., 'c', $3 \mathrm{~mm}$ (WAMC 28347). Same data as holotype.

\section{Diagnosis}

Pleonites: with few dorsal setae. Head: rostrum weak; lateral cephalic lobes moderately projecting, very broad; no antennal sinus present; eyes absent. First antenna: elongate, longer than A2; ratio of peduncular articles 6:5:2; accessory flagellum 2 articulate. Second antenna: very short; flagellum much shorter than peduncle; calceoli absent. Upper lip: symmetrical. Lower lip: with inner lobes. Mandibles: accessory blades (rakers) very few (6) on right with interraker plumose setae between each main raker; both mandibles with no additional serrations beyond rakers; mandibular palp reduced, 2 articulate; ratio of articles 1:1, article 1 not setose, terminal article linear, subtruncate, apical setae 2 E. Maxillae: well setose medially; inner plates of maxillae 1-2 poorly covered with pubescence; inner plate of maxilla 1 ovate with 5 medial setae, outer plate with denticulate setae, palps symmetric, with thin apical setae; both plates of second maxilla with apical setae of medium length; inner plate with row of medial setae extending onto face apically, other medial setae absent, medial and lateral margins poorly covered with pubescence.
Maxilliped: inner plate very long with distal row of several setae and 3 blunt naked setae, and short medial row of plumose setae; outer plate large, with few distal plumose setae, continuous without a blunt naked tooth seta; medial margin carved into sinuosities, spineless; sub-marginal face with pairs of setae; palp articles 2-3 weakly setose laterally, article 2 moderately setose medially, article 3 with setae or comb rows of setae near the base of the dactyl, apex weakly produced, dactyl unguiform, with moderate length nail. Coxae 1-7: short, broader than long, with few posterior setae; coxa 1 not expanded below; coxa 4 not excavate posteriorly; coxa 5 as long as 4. Pereopods: $3-4$ of proportions similar to pereopods 5-7; posterior seta sets on article 6 of pereopods $3-4$ unevenly spaced. Pleopods: similar; peduncles with few setae each; rami extending equally, basomedial setae of inner rami bifid; retinaculae 2 , no accessory retinaculum present. Gnathopods: 1-2 diverse; dactyls lacking inner tooth seta, lacking nail. First gnathopod: small, feeble, without rastellate seta of article 4; carpus longer than propodus, not lobate; merus lacking hyaline lobe; palm transverse, setae simple, some bearing trigger hairs and thus asymmetrically bifid, some apically dentate; setae at corner of palm = lateral 2 long apically bifid, medial 2-5 short, robust, apically bifid; setae along palm sparse and simple. Second gnathopod: weakly enlarged, carpus short and lobate, propodus of medium enlargement and ovate; palm oblique, irregularly spinose and sparsely setose, defining corner with 1 lateral long apically bifid seta. 1 medial robust apically bifid seta. Pereopods 5-7: moderately elongate; article 2 moderately expanded, ovato-rectangular, postero-ventrally extended but not lobate; dactyls of pereopods 3-7 lacking accessory spinules. Gills: coxae $2-6$ each with flask-shaped gill; coxal gill 6 not reduced. Epimera: postero-ventral tooth of epimera 1-3 absent; posterior margins smooth, and sparsely setulose; E2-3 bearing facial setae near ventral margin. Urosome: ventro-distal seta on urosomite 1 at base of uropod 1 absent. Uropods: apico-lateral corner of peduncles on uropods 1-2 with 2 and 2 setae; dorsal margins with setae; medial margin of uropod 1 with 2 apical setae, rami extending subequally; outer ramus of uropod 2 shortened; uropod 1 with basofacial seta; most rami of uropods 1-2 with single seta rows; medial setae of outer ramus of uropod 3 sparse, without sub-distal peduncular setae; uropod 3 strongly extended, parviramous, peduncle short, outer ramus 2 articulate, huge; inner ramus scale like, reaching to M0.25 on article 1 of outer ramus. Telson: longer than broad; cleft $90-100 \%$; lobes weakly convex laterally, with sub-apical setation; setae, where present, lateral; single lateral penicillate setules at M0.6 to M0.7 on each side. 


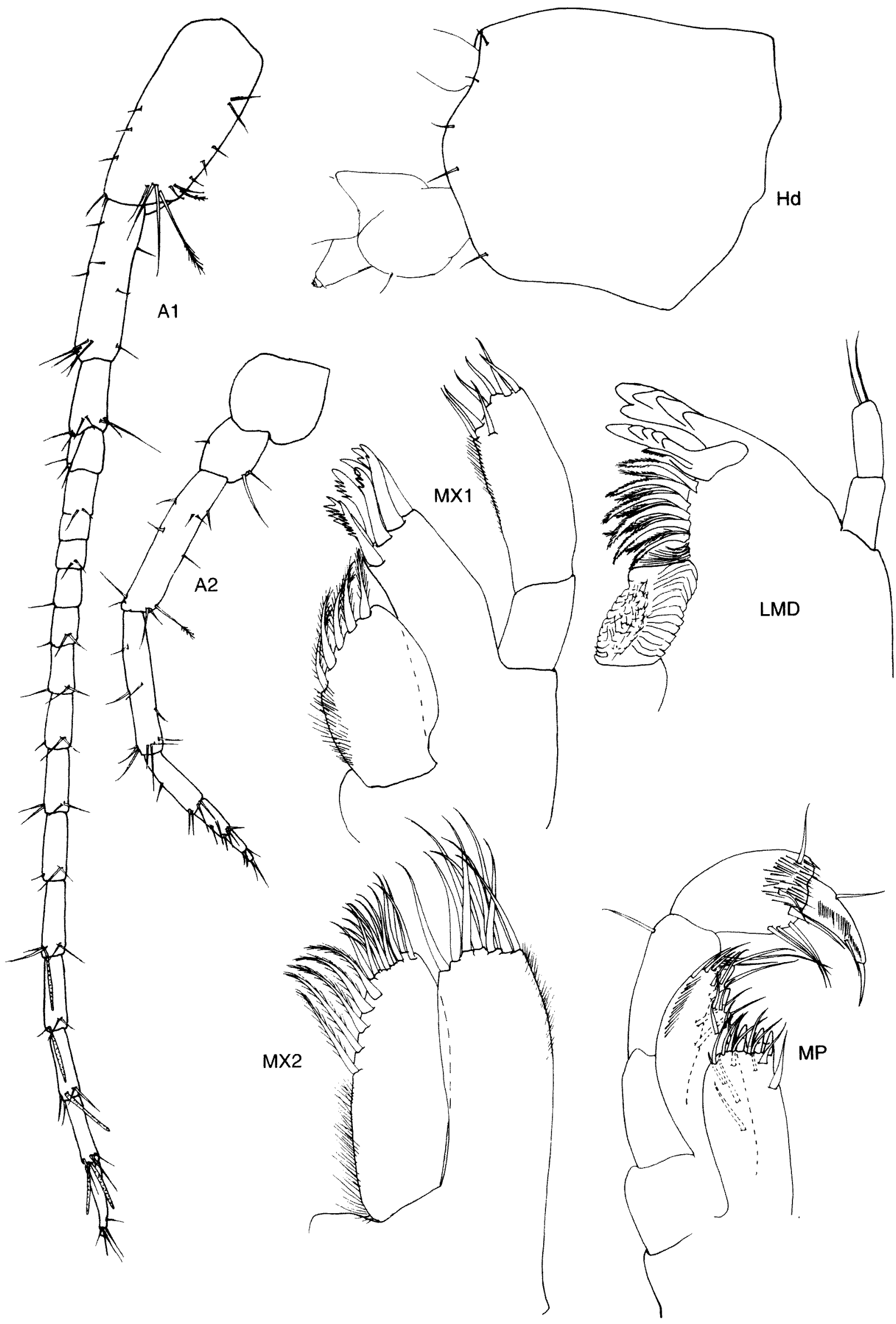

Figure 7 Nedsia halletti sp. nov. Holotype, male $4 \mathrm{~mm}$. Head, antennae, mandibles, maxillae and maxilliped. 


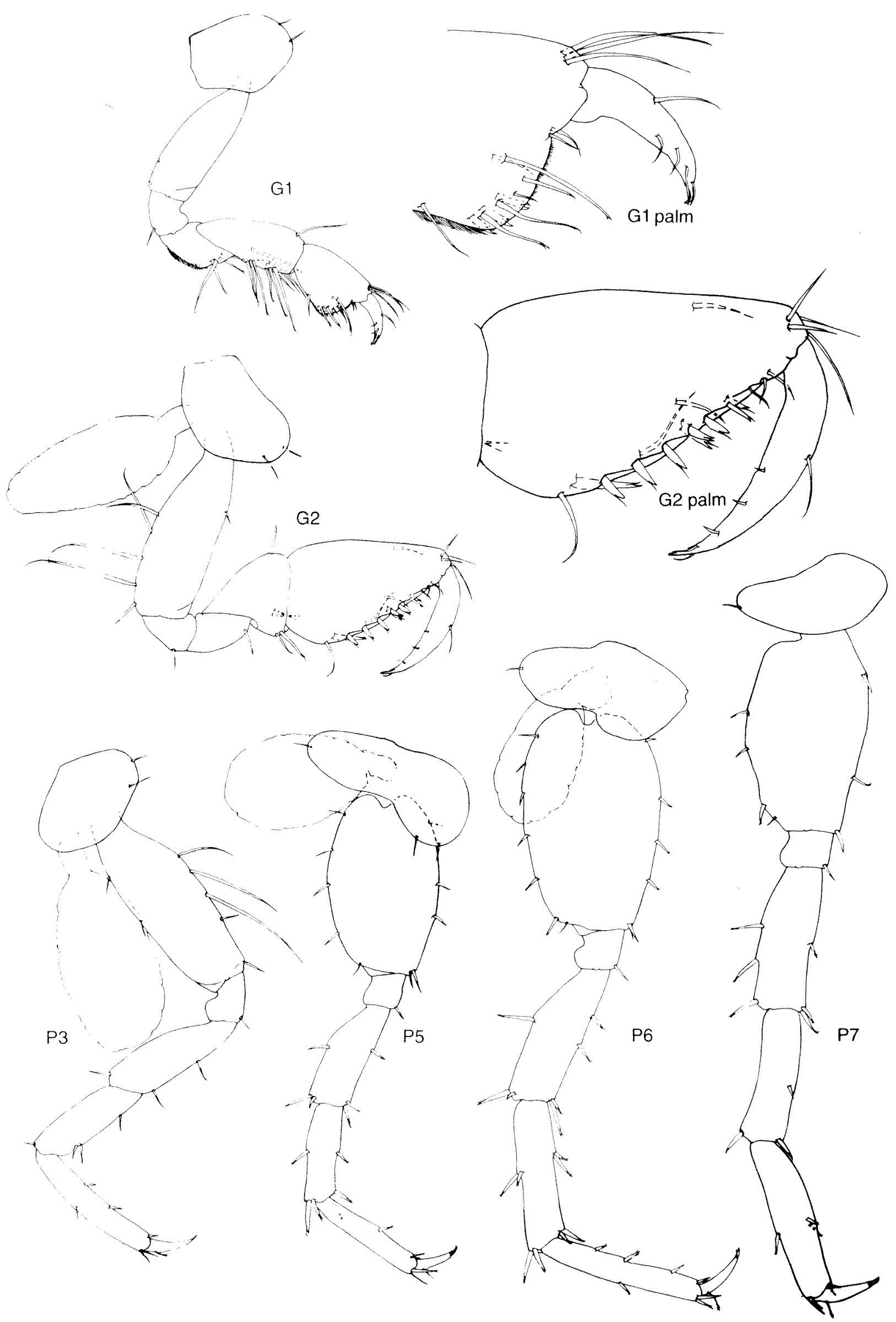

Figure 8 Nedsia halletti sp. nov. Holotype, male $4 \mathrm{~mm}$. Gnathopods, gnathopodal palms, coxa 5, pereopods 3,4,6,7. 
Description of holotype (male " $a$ ")

Body (Figure 7): $4 \mathrm{~mm}$. Urosome: poorly armed dorsally. Head: rostrum obsolescent; antennal sinus absent; eyes absent. First antenna (Figure 7): length $0.4 x$ body, $1.5 x \mathrm{~A} 2$; flagellum longer than peduncle (1.8x); peduncular article 3 shortest, article 1 longest, ratio of lengths $=62: 48: 20$; setae sparse; flagellum of 16 articles; aesthetascs present on articles 11-14; calceoli absent; accessory flagellum 2 articulate, reaching M0.9 of article 1 of primary flagellum, article 2 tiny; articles of primary flagellum not uniform, but progressively longer, sparsely setulate. Second antenna (Figure 7): length $0.25 \mathrm{X}$ body; peduncle much longer than flagellum, articles 4-5 equally long (45:42), articles 3-5 with weak ventral setation, lacking robust setae; flagellum short (0.4x peduncle), 4 articulate, no calceoli. Upper lip: margin not excavate. Mandibles (Figure 7): left mandibular palp 2 articulate, articles sub-equal in length, article 2 with 2 long apical setae (E2) only; incisor 5 toothed; lacinia mobilis with 5 denticles, bearing a postero-facial rugose seta; 6 setose accessory blades; molar without distal plumose seta, triturative; cluster of fine setae between accessory blades and base of molar; (right mandibular incisor 5 toothed; lacinia mobilis bifid, broad, finely denticulate; accessory blades of 6 plumose spines; palp 2 articulate). Lower lip: bearing distinct inner lobes. First maxilla (Figure 7): palp article 2 with 6 thin apical and one disto-facial setae, all naked; outer plate bearing 7 denticulate setae; inner plate ovate, bearing 5 apico-medial plumose setae, baso-medial margin pubescent. Second maxilla (Figure 7): outer plate bearing pubescence apicolaterally; inner plate pubescent on baso-medial margin, bearing a row of 5 medial marginal tending disto-facial plumose setae. Maxilliped (Figure 7): nail of palp moderately long ( 0.3 of dactyl), palp article 3 with few thin setae at dactylar base, none proximal, apex slightly extended and facially pubescent; outer plate medial margin bearing 4 scallop like indentations distally, a medio-facial row of strong naked setae, 3 apico-lateral naked setae and disto-facial pubescence laterally: inner plate without ventro-facial seta or short spur, with a pair of sub-marginal medial plumose setae apicofacially, three naked tooth setae apically and 4 thin naked apical long setae. First gnathopod (Figure 8): coxal plate with two short setae apically and none postero-ventrally; article 4 pubescent and slightly bulbous posteriorly; carpus not lobate, longer than wide; propodus trapezoidal, expanding slightly apically, longer than wide, the posterior edge bearing a single slender seta at M0.6; corner of palm rounded, bearing 2 long, naked, apically bifid setae laterally and 3 stout bifid setae medially, palm slightly convex, bearing few long slender setae; dactyl reaching to the palmar corner. Second gnathopod (Figure 8): coxa bearing 2 anterior setae only; palmar corner marked laterally by a single long slender seta, medially by 1 long, robust trigger seta; palm bearing 5 robust and one slender trigger setae and 2 short slender simple setae adjacent the dactylar base laterally, a single mid-palmar robust trigger seta, 2 sub-marginal slender setae and 1 small seta basal to the dactyl medially; dactyl bearing 3 small sub-marginal setae distally. Pereopods (Figure 8): coxa 3 with 2 anterior setae, similar to coxa 1, P3 longer than G2; P3-5 approximately equal, articles 4,5 sparsely setose posteriorly, with only one locking seta; P5-7 similar but consecutively elongate, each with paired locking setae distal on article 6; P7 anterior setae of articles 5 and 6 displaced inward by keel-like expansion of the segment; coxae 5-7 bearing 1,1,1 setae on posterior lobes, 2,0,0 anterior setae, article 2 weakly expanded, most on P7, not lobate, but extended posteriorly and bearing few setae; dactyls of P3-7 simple, naked except for an anterior basal penicillate setule, with the addition of an outer terminal setule on P5-7. Gills: coxae 2-6 with flask shaped gills, gill of C3 largest. Pleopods (Figure 10): retinaculae 2 per pleopod, no accessory retinaculae; peduncles each bearing 2 apical setae; rami extending equally, the inner with 5:5:5 articles, the outer with 7:6:6; no bifid setae on basal articles. Epimera (Figure 10): E1-2 postero-ventrally rounded, E3 sub-quadrate; posterior margins scarcely convex on 1-2, straight on E3, all smooth, with no setae except a single seta marking the posterior corner; E2-3 with 1 and 2 weak submarginal ventral setae, lacking lateral oblique ridge. Pleon (Figure 10): pleonites 2-5 with dorso-lateral posterior setae; pleonite 6 with 1 lateral and 1 distoventral setae. Uropods (Figure 10): uropod lengths relative to $\mathrm{U} 1$ are $\mathrm{U} 2=0.6 \mathrm{X}, \mathrm{U} 3=1.5 \mathrm{X}$; basal face of $\mathrm{U} 1$ bearing a robust seta; peduncle length $1.4 \mathrm{X}$ inner ramus, the outer margin bearing 2 apico-distal setae and a row of 3 mid-dorsal setae, the medial apex bearing 2 setae and the medial margin bearing 3 setae; rami of sub-equal length (inner : outer = 92:85), both naked except for a single mid-dorsal seta medial on the inner ramus and lateral on the outer ramus; both rami with 5 terminal setae; U2 peduncle length $0.8 x$ inner ramus, bearing a single apico-lateral seta and 2 marginal setae; inner ramus length $1.2 x$ outer, the medial margin bearing 2 setae only, with 4 terminal setae; outer ramus shorter, bearing a single marginal seta and 4 terminal setae; U3 strongly extended beyond uropods 1-2 in entire animal; peduncle length $0.3 x$ outer ramus, shorter than urosomite 3 , bearing paired latero-distal marginal setae and 1 lateral seta, 1 apico-medial seta, and 1 small mid-medial sub-marginal, facial seta; outer ramus proximal article with few marginal setae, some paired, laterally pubescent, and 2 apico-lateral setae; medially 3 apical setae, 3 marginal setae; 2 apical setae basal to the second 


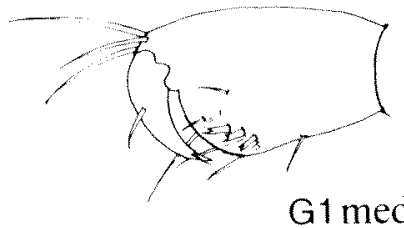

G1 med
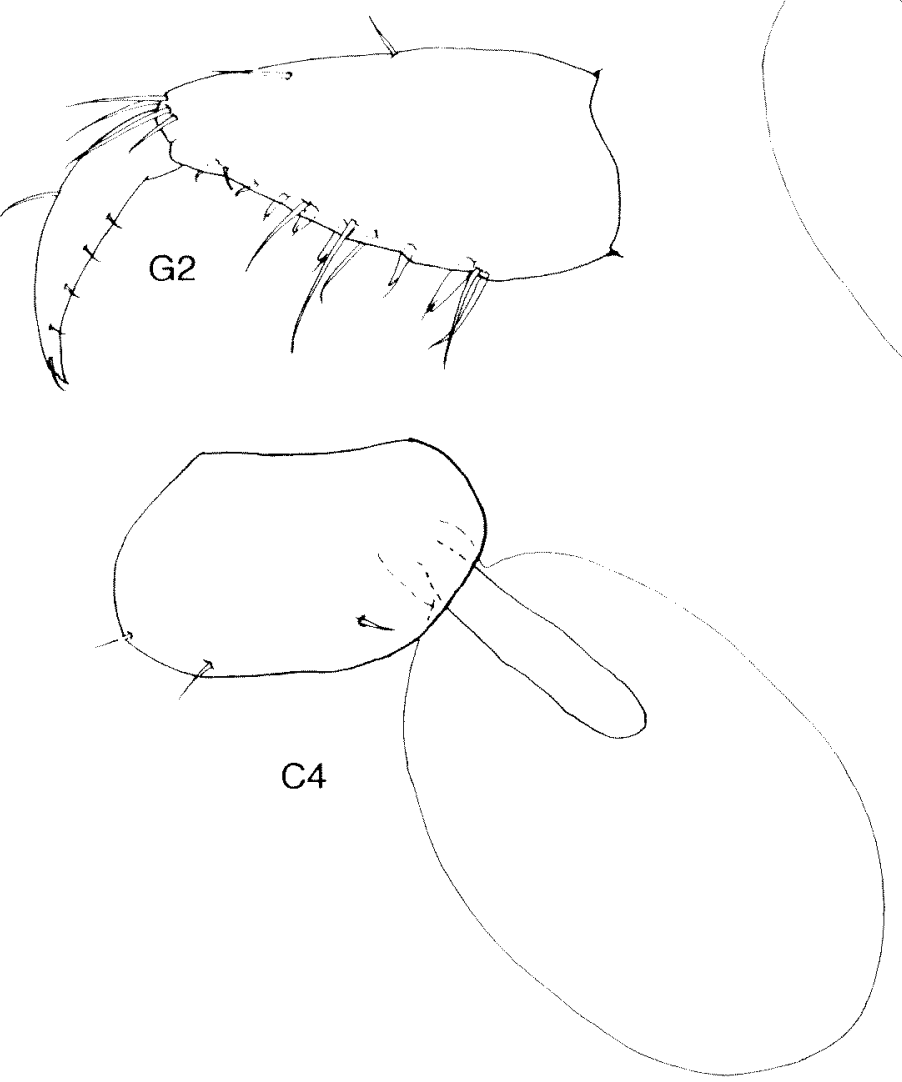

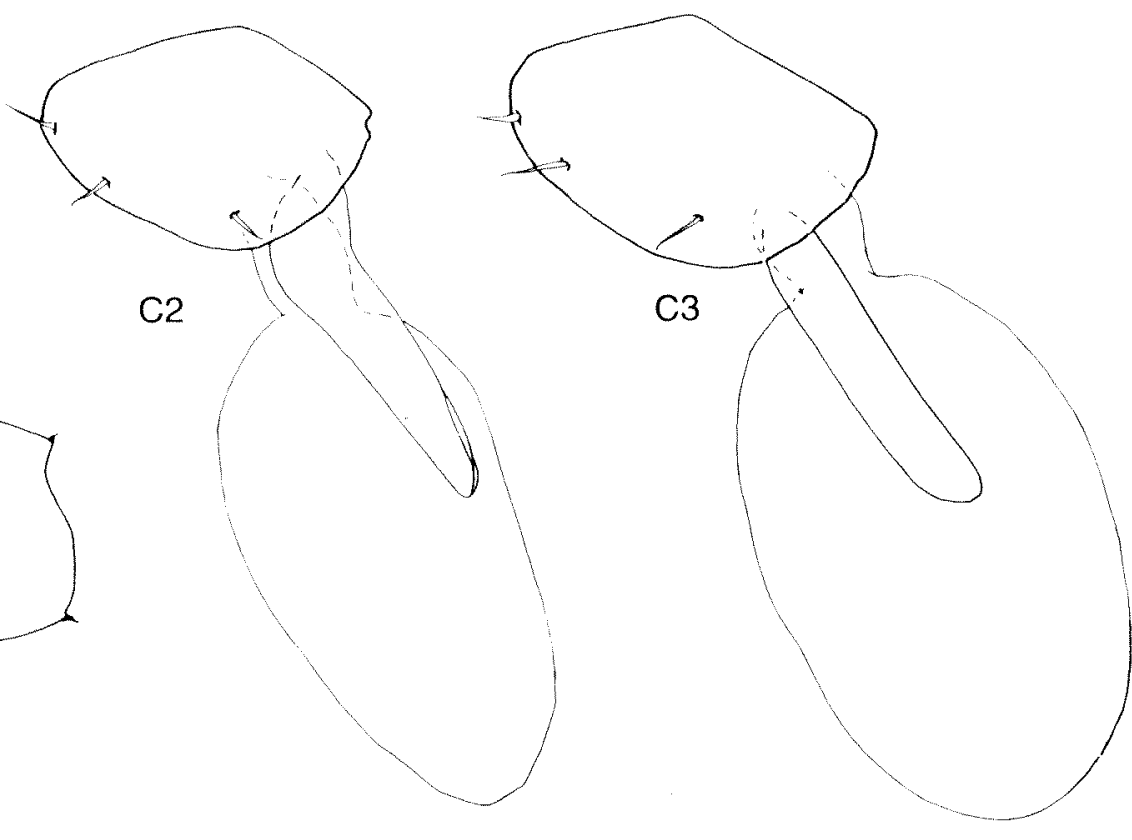

Figure 9 Nedsia halletti sp. nov. Allotype, female ' $b$ ' $4 \mathrm{~mm}$. Gnathopodal propodi, coxae 2-5 showing coxal gills and oostegites.

article; article two equal in length to the first, similarly armed, lacking pubescence, terminating in a cluster of 8 mixed robust and slender setae; inner ramus scale like, sub-quadrate, length $0.13 x$ outer ramus, bearing paired apico-medial setae. Telson (Figure 10): length $1.8 \mathrm{x}$ width, widest at the base, sub-equal in length to urosomite 3 , cleft $100 \%$; apices slightly notched laterally; sub-apices with 2 long plumose setae, 1 right and 2 left sub-marginal medial setae at M0.7 and 1 lateral seta at M0.5; no other dorsal setae.

\section{Description of allotype (female ' $b$ ')}

Body: length $4 \mathrm{~mm}$. Pleonite 6 bearing single dorsolateral setae. First antenna: aesthetascs absent. Second antenna: length of peduncle $4=0.9 x$ peduncle 5 ; flagellum length less $(0.7 x)$ than peduncle. First gnathopod (Figure 9): propodus small, trapezoidal, expanding apically, $0.6 \times \mathrm{G} 2$, bearing three long slender lateral setae, and 3 robust apically bifid setae medially, with few other setae; coxal plate bearing two anterior and one facial postero-ventral setae. Second gnathopod (Figure 9): propodus large, ovate, palm acute, marked at corner by an elongate slender seta laterally and one long, slender and one robust apically bifid setae medially; palm bearing additionally two long slender and one short setae laterally, and four robust apically bifid, one long slender and two short setae medially; coxal plate similar to G1. Coxae of pereopods G2 to P6 each bearing a single flask shaped gill, and coxae 2-5 additionally bearing a narrow, strap like, naked oostegite. Pleopods: bearing 2 retinaculae, without accessory retinaculae; pleopodal inner rami of $6,6,5$ articles, outer rami of 7,6,6 articles. Uropod: first uropod length relative to $U 2=1.7 \mathrm{x}$; peduncle of $\mathrm{U} 1$ $1.3 \mathrm{X}$ length of inner ramus, of U2 $0.8 \mathrm{x}$ length of inner ramus; Telson: (Figure 10): longer than wide; ventral face with a single seta medial sub-marginal at M0.77; length $2.2 x$ width; lateral margin bearing 
three setae at M0.3, M0.6, M0.8; dorsal sub-apices bearing a pair of elongate penicillate setae.

\section{Description of paratype (male ' $c$ ')}

Body length $3 \mathrm{~mm}$. First antenna: length $0.5 x$ body, much longer than A2; peduncle shorter than flagellum, flagellum of 16 articles, bearing aesthetascs on articles 10-15. Second antenna: peduncle article 4 shorter than article $5(0.8 x)$, longer than flagellum (3x); flagellum of 4 articles. Mandible: palp short, two articulate, articles subequal in length. Gnathopods and Pereopods: similar to type (male ' $a$ '). Pleopods: peduncles each bearing 2 retinaculae and no accessory retinaculae; inner rami of 5,5,4 articles, outer rami of 6,6,5 articles. Epimera: epimera 1-2 postero-ventral corners rounded, the posterior margins slightly convex; epimeron 3 postero-ventrally sub-quadrate posterior margin straight; each postero-ventral corner marked by a small seta, each posterior margin naked; epimeron 1 without ventero-facial setae, epimera $2-3$ bearing 2 and 4 ventero-facial setae, respectively. Pleon: pleonites 1-3 each bearing 2 distal setae dorsally and 1 disto-lateral seta; pleonite 4 bearing 2 small dorso-distal setae, pleonite 5 single small dorsolateral setae and pleonite 6 single dorso-lateral and disto-ventral setae. Uropods: uropod 1 length relative to uropod $2=1.8 \mathrm{x}$. Uropod 1:peduncle bearing a strong baso-facial seta, peduncle length $1.2 x$ inner ramus, bearing 2 dorso-medial and dorso-lateral setae as well as 2 apico-medial and apico-lateral setae; inner ramus bearing only 4 apical setae; outer ramus bearing a single dorsolateral seta and 4 apical setae. Uropod 2: peduncle $0.75 \mathrm{x}$ length of inner ramus, bearing 1 dorso-medial and 4 apical setae; inner ramus longer than outer ramus (1.2x), bearing a single dorso-medial seta and 4 apical setae; outer ramus bearing 2 dorso-lateral setae and 5 apical setae. Telson: similar to the holotype (male ' $a$ ').

\section{Distribution}

Underground water in L32J old water well (field collection BES3441); disused, steel cased water bore at altitude $50 \mathrm{~m}$ above AHD, in the central heights, Barrow Island, ground-water $2 \mathrm{~m}$ deep at about sea level.

Barrow Island, Western Australia, 20 $48^{\circ} 34 \mathrm{~S}^{\prime \prime}$, $115^{\circ} 22^{\prime} 42^{\prime \prime} \mathrm{E}$.

\section{Etymology}

Named for Keith Hallett who generously imparted of his knowledge of the ground water environment of Barrow Island.

\section{Relationships}

$N$. halletti differs from all other described species of the genus Nedsia in: primary flagellum of the first antenna of 16 articles; mandibles bear 7 setose accessory blades; the palm of the first gnathopod bears 2 long naked lateral setae adjacent the corner and 3 other long setae along the palm, and 3 stout bifid setae medially as well as a single slender seta basal to the dactyl; the second gnathopodal corner is marked by a single slender seta laterally and a long robust trigger seta medially, the palm bearing 5 robust and 1 slender trigger setae as well as 2 slender setae basal to the dactyl laterally and single robust and slender trigger setae as well as 3 other slender setae medially; the uropodal rami bear 5:5:5 medial articles and 7:6:6 lateral articles; the second article of the outer ramus of the third uropod is as long as the first, and bears 7 terminal setae.

As well as the above universal differences, $N$. halletti differs from $N$. macrosculptilis and $N$. sculptilis in lacking posterior serration of the pleon, in the elongate first rather than the second article of the first antennal peduncle, and the non-fused first two articles of the primary flagellum; $N$. halletti differs from N. macrosculptilis, N. sculptilis, N. urifimbriata and $N$. douglasi in that the primary flagellum of the first antenna bears aesthetascs; the second antenna flagellum is 4 articulate rather than 5 ; the mandibular palp is of 2 equally short articles unlike N. straskraba, N. hurlberti, N. urifimbriata, N. fragilis and $N$. douglasi in which the first article is shorter than the second; the second article of the mandibular palp bears 2 only $\mathrm{E}$ setae unlike $N$. straskraba which also bears $2 \mathrm{D}$ setae; the incisor is 5 toothed compared with 4 in N. hurlberti, and the left lacinia mobilis bears 5 denticles and the mandible pubescent, unlike N. hurlberti, N. straskraba and N. humphreysi which each have 4 denticles and also, along with $N$. urifimbriata, lack mandibular pubescence. The palp of the first maxilla bears 7 apical setae, unlike all other Nedsia spp. except $N$. hurlberti; the outer plate of the second maxilla is pubescent, thus differing from $N$. straskraba, $N$. humphreysi, N. fragilis and N. stefania, as well as on the inner plate, unlike N. humphreysi and N. fragilis. The first coxal plate bears 2 apical setae, unlike $N$. hurlberti, N. humphreysi and $N$. fragilis and $N$. douglasi, and is without posterior setae whereas $N$. straskraba, N. urifimbriata and $N$. fragilis each bear 1 , and $N$. douglasi two; the second coxa is similar to the first and different from N. straskraba, N. fragilis, $N$. macrosculptilis and $N$. douglasi, although $N$. hurlberti bears no posterior setae on the second coxa; coxa 3 differs from all except $N$. sculptilis. The lengths of pereopods 3-4 are approximately equal, unlike $N$. sculptilis; P5-7 bear paired locking setae, not single on P5 and P7 as in N. straskraba and the second articles are approximately equal, not progressively expanded, as in $N$. straskraba, N. hurlberti and $N$. humphreysi. Pleopods bear no accessory retinaculae as do $N$. straskraba and $N$. douglasi; the first epimeron is without ventro-facial 


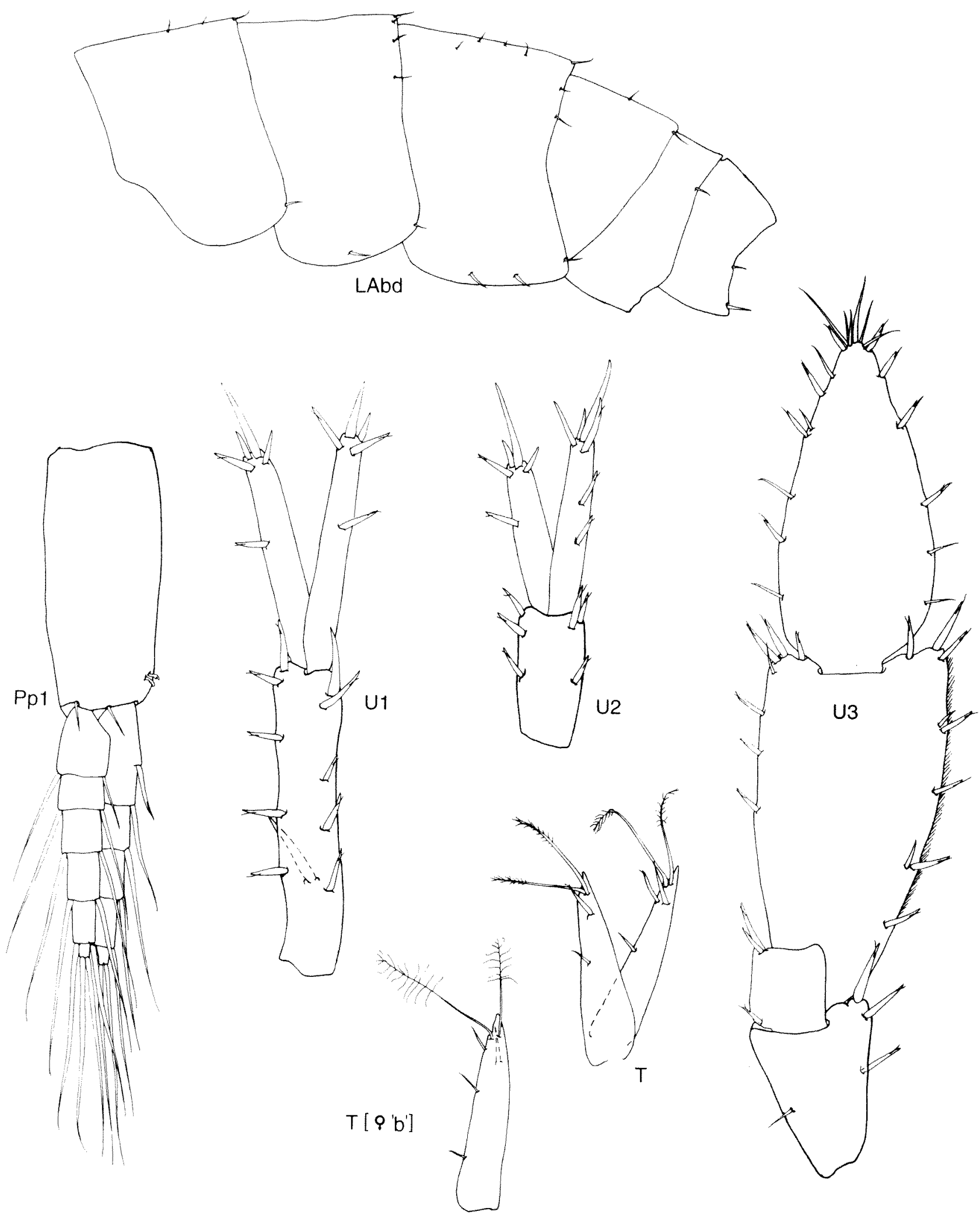

Figure 10 Nedsia halletti sp. nov. Holotype, male $4 \mathrm{~mm}$. Abdomen, pleopod 1, uropods 1-2 and telson.

setae unlike $N$. douglasi, which bears 1 ; the second epimeron bears a single ventral seta, unlike all other species except $N$. chevronia, and the third epimeron 2 ventral setae, similar only to $N$. straskraba; pleonites 4-5 bear single dorsolateral posterior setae, differing from all but $N$. urifimbriata, $N$. stefania and $N$. chevronia; the peduncle of the first uropod bears 1 apico-distal, 4 mid-dorsal and 1 apico-medial setae similar only to $N$. hurlberti, rami are sub-equal in length, unlike $N$. sculptilis and $N$. fragilis, naked except for a single mid-dorsal seta on the inner ramus rather than paired setae as in $N$. 
hurlberti and N. urifimbriata, and bearing 4 apical setae similar only to $N$. stefania, $N$. chevronia, $N$. fragilis and N. humphreysi, all others bearing 5 apical setae; likewise, the second uropod differs from all other species. The peduncle of the third uropod is proportionally longer than in other species excepting $N$. chevronia, bears paired disto-lateral marginal setae rather than single setae as in $N$. straskraba and N. urifimbriata, no sub-apical seta, compared with 3 in $N$. urifimbriata and 1 in $N$. straskraba; the first article of the outer ramus differs, in numbers of marginal setae from $N$. douglasi, in numbers of apical setae from $N$. macrosculptilis, $N$. chevronia, $N$. straskraba and $N$. urifimbriata; and the second article is equal to, not shorter than, the first, unlike all other species, bears 7 terminal setae, more than any other species, and the inner ramus bears paired apico-medial setae, thus differing from $N$. straskraba. Telsonic lobes are more slender than all but $N$. humphreysi and $N$. macrosculptilis, are without dorsal setae as in $N$. douglasi, cleft $100 \%$, unlike N. straskraba (85\%), and bear single lateral penicillate setules on either lobe at M0.5, more basal than other species excepting $N$. urifimbriata.

\section{Remarks.}

The three new species of the genus Nedsia described here are derived from samples taken at seven locations on Barrow Island between October 1998 and April 1999 (Appendix 1). The nature of the habitat and methods of collection of these stygobionts, which are small, fragile, and some of the appendages attenuate, are such that complete specimens are difficult to obtain; often, also, the majority are juveniles, and usually few specimens are collected at any one site. Consequently, material from several locations could not be identified with absolute certainty. Nevertheless, much of the material has been assigned to species wherever possible, based upon the presence of gross characters. Thus, for example, $N$. sculptilis or $N$. macrosculptilis, characterised by unique sculpturing of the pleon, were recognised from 5 samplings of 4 locations. Other specimens recorded include $N$. straskraba 3 samples from one location; $N$. humphreysi -1 sample ( 1 site); and $N$. hurlberti -2 samples from 2 locations.

Barrow Island is one of the few Western Australian marine karst areas studied in any detail (Humphreys, 1993a,b; 1999, 2000), and, like other stygobiont sites in Western Australia where any intensity of sampling has been carried out (Bradbury and Williams, 1997; Bradbury, 2000; Watts and Humphreys, 1999, in press), has proved to be a significant, species rich region. Further sampling may yield more species from the Island: indeed several of the samples examined here included specimens which could not be reliably identified because of damage or immaturity, yet had the appearance of new, undescribed taxa.

Keys to the first seven of these species of the genus Nedsia were set out in Bradbury and Williams (1996a, 1999). From these, N. chevronia keys to position 6, then: coxa 1 without setae; telson without dorsal setae; maxillipedal outer plate length $2.4 \mathrm{x}$ width. $N$. stefania keys to position 3, then: epimera 1 bearing disto-lateral setae; peduncle of first uropod bearing facial seta; first gnathopod palmar corner rounded; outer plate of maxilliped not apically rounded, medial cusps strong. $N$. hallettii keys to position 6 , then: coxa one bearing anterior, but no posterior, setae; telson bearing dorsal setae; maxillipedal outer plate length $2.9 x$ width.

\section{ACKNOWLEDGEMENTS}

I wish to thank Dr W.F. Humphreys of the Western Australian Museum for making this material available for analysis. Field work by W.F. Humphreys was supported by Western Australian Petroleum Pty Ltd (now Chevron Australia Pty Ltd). Stephan Fritz facilitated the visits to Barrow Island. This work was funded by Chevron Australia Pty Ltd and the Western Australian Museum. I sincerely thank Dr Traudl Krapp for her helpful refereeing of the manuscript. This paper is a contribution to DIVERSITAS-IBOY project, "Exploration and Conservation of Anchialine Faunas".

\section{REFERENCES}

Barnard, J.L. and Barnard, C.M. (1983). Freshwater Amphipoda of the World. 1. Evolutionary Patterns. II. Handbook and Bibliography. Hayfield Associates, Mount Vernon, Virginia. Pp. 1-830.

Barnard, J.L. and Williams, W.D. 1995. The taxonomy of Amphipoda (Crustacea) from Australian fresh waters. Part 2. Records of the Australian Museum 47: 161-201.

Bradbury, J.H. (2000). Western Australian Stygobiont Amphipods (Crustacea: Paramelitidae) from the Mt. Newman and Millstream Regions. Records of the Western Australian Museum, Supplement No. 60: 1101.

Bradbury, J.H. and Eberhard S.M., 2000. A new stygobiont melitid amphipod from the Nullarbor Plain. Records of the Western Australian Museum 20:3950.

Bradbury, J.H. and Williams, W.D. (1996a). Freshwater amphipods from Barrow Island, Western Australia. Records of the Australian Museum 48: 33-74.

Bradbury, J.H. and Williams, W.D. (1996b). Two new species of anchialine amphipod (Crustacea: Hadziidae: Liagoceradocus) from Western Australia. Records of the Western Australian Museum, 17: 395-409.

Bradbury, J.H. and Williams, W.D. (1997). The amphipod stygofauna of Australia: description of new taxa 
(Melitidae, Neoniphargidae, Paramelitidae), and a synopsis of known species. Records of the Australian Museum 49: 249-341.

Bradbury, J.H. and Williams, W.D. (1999). Key to and checklist of the inland aquatic amphipods of Australia. Technical Reports of the Australian Museum 14: 1-21.

Holsinger, J.R. (1994). Pattern and process in the biogeography of subterranean amphipods. Hydrobiologia 287: 131-145.

Humphreys, W.F. (1993a). Cave fauna in semi-arid tropical Western Australia: a diverse relict wet-forest litter fauna. Mémoires de Biospéologie 20: 105-110.

Humphreys, W.F. (1993b). Stygofauna in semi-arid tropical Western Australia: a Tethyan connection? Mémoires de Biospéologie 20: 111-116.

Humphreys, W.F. (1999). Relict stygofauna living in sea salt, karst and calcrete habitats in arid north western Australia contain many ancient lineages. In 'The other $99 \%$. The Conservation and Biodiversity of Invertebrates' 219-27. Eds. Winston Ponder and Daniel Lunney, 1999. Transactions of the Linnean Society of New South Wales, Mossman.

Humphreys, W.F. (2000). Chapter 30. The hypogean fauna of the Cape Range peninsula and Barrow
Island, north western Australia. Pp. 581-601. In: H. Wilkens, D.C. Culver and W.F. Humphreys (eds). Ecosystems of the World, vol. 30. Subterranean Ecosystems. Elsevier, Amsterdam.

Karaman, G.S. (1969). XXII Beitrag zur Kenntnis der Amphipoden. Über einige Formen des Genus Sarathrogammarus (Gammaridae) aus Afghanistan. Acta Musei Macedonici scientarum Naturalium Skopje 11 (11): 195-208.

Paine, A.G.L. (ed.), (1990). Australia. Evolution of a continent: 1-97. (Australian Government Publishing Service, Canberra).

Watts, C.H.S. and Humphreys, W.F. (1999). Three new genera and five new species of Dytiscidae (Coleoptera) from underground waters in Australia. Records of the South Australian Museum 32: 121-142.

Watts, C.H.S. and Humphreys, W.F. (2000). Six new species of Nirridessus and Tjirtudessus (Dytiscidae; Coleoptera) from underground waters in Australia. Records of the South Australian Museum 33: 127-144.

Manuscript received 22 November 2000; accepted 26 September 2001.

Appendix 1 Collection number, site details and locations.

\begin{tabular}{|c|c|c|c|c|c|c|c|}
\hline WAM \# & Site & Collector & Details & Date & No. & Latitude & Longitude \\
\hline 3395 & $\mathbf{A}$ & WFH/SME & MW15/SB36 & $22 / 10 / 98$ & 17 & $20^{\circ} 46^{\prime} 58^{\prime \prime} \mathrm{S}$ & $115^{\circ} 27^{\prime} 53^{\prime \prime} \mathrm{E}$ \\
\hline 3424 & & WFH/SME & MW15/SB36 & $23 / 10 / 98$ & 5 & & \\
\hline 3397 & B & WFH/SME & MW17 & $22 / 10 / 98$ & 3 & $22^{\circ} 46^{\prime} 43^{\prime \prime}$ & $115^{\circ} 28^{\prime} 14^{\prime \prime}$ \\
\hline 3407 & C & WFH/SME & L8, old water supply well & $22 / 10 / 98$ & 2 & $20^{\circ} 49^{\prime} 01^{\prime \prime}$ & $115^{\circ} 23^{\prime} 40^{\prime \prime}$ \\
\hline 3420 & & WFH/SME & L8, old water supply well & $23 / 10 / 98$ & 2 & & \\
\hline 3439 & & WFH/SME & L8, old water supply well & $24 / 10 / 98$ & 1 & & \\
\hline 6969 & & K.Hallett & L8, old water supply well, mid point & $13 / 01 / 99$ & 1 & & \\
\hline 6980 & & K.Hallett & L8, old water supply well, surface & $13 / 01 / 99$ & 1 & & \\
\hline 7301 & & K.Hallett & L8,old water supply well, surface & $15 / 04 / 99$ & 1 & & \\
\hline 7305 & & K.Hallett & L8, old water supply well, middle & $15 / 04 / 99$ & 1 & & \\
\hline 3411 & $\mathbf{D}$ & WFH/SME & M62, tank supply pump \#2, surface & $22 / 10 / 98$ & 1 & $20^{\circ} 49^{\prime} 08^{\prime \prime}$ & $115^{\circ} 24^{\prime} 24^{\prime \prime}$ \\
\hline 3431 & & WFH/SME & M62, tank supply pump \#2, surface & $23 / 10 / 98$ & 1 & & \\
\hline 6987 & & K.Hallett & M62, tank supply pump \#2, surface & $13 / 01 / 99$ & 1 & & \\
\hline 6990 & & K.Hallett & M62, tank supply pump \#2, surface & $13 / 01 / 99$ & 3 & & \\
\hline 3441 & $\mathbf{E}$ & WFH/SME & L32J old water well & $24 / 10 / 98$ & 8 & $20^{\circ} 48^{\prime} 34^{\prime \prime}$ & $115^{\circ} 22^{\prime} 42^{\prime \prime}$ \\
\hline 3462 & & WFH/SME & L32J old water well & $25 / 10 / 98$ & 3 & & \\
\hline 6983 & $\mathbf{F}$ & K.Hallett & LAN, unused anode well, surface & $13 / 01 / 99$ & 1 & $20^{\circ} 48^{\prime} 22^{\prime \prime}$ & $115^{\circ} 23^{\prime} 21^{\prime \prime}$ \\
\hline 6984 & & K.Hallett & L4N, unused anode well, mid point & $13 / 01 / 99$ & 1 & & \\
\hline 7308 & & K.Hallett & L4, bottom sample & $16 / 04 / 99$ & 1 & & \\
\hline 7001 & G & K.Hallett & M13, new unused anode well, surface & $13 / 01 / 99$ & 1 & $20^{\circ} 49^{\prime} 02^{\prime \prime}$ & $115^{\circ} 24^{\prime} 44^{\prime \prime}$ \\
\hline
\end{tabular}

$\mathrm{WFH}=$ W.F.Humphreys; SME = S.M.Eberhard. WAM = Western Australian Museum. 